\title{
The role of Bruton's kinase inhibitors in chronic lymphocytic leukemia: Current status and future directions
}

\author{
Tadeusz Robak1+*, Magda Witkowska² + , Piotr Smolewski† ${ }^{2}$
}

\begin{abstract}
${ }^{1}$ Department of Hematology, Medical University of Lodz, 93-510 Lodz, Poland; robaktad@csk.umed.lodz.pl (R.T.)

2Department of Experimental Hematology, Medical University of Lodz, 93-510 Lodz, Poland; piotr.smolewski@umed.lodz.pl (P.S.); magdalena.witkowska@umed.lodz.pl (M.W.)
\end{abstract}

† All authors contributed equally.

*Correspondence:orrespondence: e-mail: robaktad@csk.umed.lodz.pl; tel: +48 42 689-51-91; fax:+ 4842 689-51-92

Tadeusz Robak Orcid http://orcid.org/0000-0002-3411-6357

Simple Summary: The availability of Bruton's tyrosine kinase (BTK) inhibitor ibrutinib has undoubtedly reshaped the initial management of chronic lymphocytic leukemia (CLL). Acalabrutinib and zanubrutinib are selective second-generation BTK inhibitors designed to have high specificity for BTK and minimize off-target effects. However, despite the positive impact of these drugs on patient outcomes, their introduction has created new practical challenges for clinicians, mainly due to their adverse events and the development of drug resistance. Therefore, new combinations of BTK inhibitors and their combinations are currently being tested. This review summarizes new data about the approved drugs and the agents in clinical development for therapeutic use in CLL.

\begin{abstract}
The use of the Bruton's tyrosine kinase (BTK) inhibitors has changed the management and clinical history of patients with chronic lymphocytic leukemia (CLL). BTK is a critical molecule that interconnects B-cell antigen receptor (BCR) signaling. BTKIs are classified into two categories: irreversible (covalent) inhibitors and reversible (non-covalent) inhibitors. Ibrutinib is the first irreversible BTK inhibitor approved by the U.S. Food and Drug Administration in 2013 as a breakthrough therapy in CLL patients. Subsequently, several studies evaluated the efficacy and safety of new agents with reduced toxicity when compared with ibrutinib. Two other irreversible, second-generation BTK inhibitors, acalabrutinib and zanubrutinib, were developed to reduce ibrutinib-mediated adverse effects. Additionally, new reversible BTK inhibitors are currently under development in an early phase studies to improve their activity and to diminish adverse effects. This review summarizes the pharmacology, clinical efficacy, safety, dosing, drug-drug interactions associated with the treatment of CLL with BTK inhibitors, and examines its further implications.
\end{abstract}

Keywords: Acalabrutinib, Bruton's tyrosine kinase, BTK, CLL, Covalent inhibitors, COVID-19, Ibrutinib, Non-covalent inhibitors, Fenebrutinib, MK1026, Pirtobrutinib, Spebrutinib, Tirabrutinib, Zanubrutinib 


\section{Introduction}

The Chronic lymphocytic leukemia (CLL) is an indolent form of small mature B-cell leukemia that predominantly affects older individuals [1,2]. It is the most common type of leukemia in Western countries, with a median age at diagnosis of 72 years. CLL is responsible for approximately $40 \%$ of all adult leukemias and $11 \%$ of all hematological malignancies. The incidence of the disease is 3.5 cases per 100,000 inhabitants per year [3]. In addition, the World Health Organization (WHO) also recognizes small lymphocytic lymphoma (SLL) as a disease entity. Its cells exhibit the same immunophenotype (CD5 + / $\mathrm{CD} 19+$ and CD5 + / CD23 +) and morphology as in CLL but does not primarily involve the bone marrow; as such, SLL is classified as a combined lymphoproliferative disease, i.e. as SLL/CLL [5]. Consequently, many clinical trials have considered CLL and SLL in the same group of malignancies. In a recent study, relative survival improved significantly for CLL patients diagnosed between 1985 and 2015 [4]. However, despite these findings and recent changes in therapeutic strategies in CLL, the disease remains incurable in the majority of patients. Most of the patients will relapse sooner or later, and some will be resistant to the treatment available.

Bruton's tyrosine kinase (BTK) is a member of the TEC kinase family [5]. It plays an important role in malignant B lymphocyte proliferation and survival in CLL [6]. BTK inhibitors (BTKi) have become a very important target in the treatment of inflammatory reactions and autoimmune diseases, as well as of B-cell malignancies, including CLL. These agents have transformed CLL management in both previously untreated and relapsed/refractory patients [7-12]. BTK inhibitors are classified into two categories: irreversible (covalent) inhibitors and reversible (non-covalent) inhibitors (Table 1) [13]. Ibrutinb, acalabrutinib and zanubrutinib are irreversible BTKi, binding covalently to the Cys481 residue in the ATP binding pocket of BTK [14]. However, most patients develop resistance to treatment with currently approved BTK inhibitors, and novel therapies are urgently needed. Ibrutinib, is a first-in-class, irreversible, oral, once-daily BTKi approved for the treatment of CLL/SLL. As a single agent, ibrutinib has led to prolonged progression-free survival (PFS) and overall survival (OS) in patients with previously-treated CLL [15]. Of the remaining irreversible BTKis, acalabrutinib and zanubrutinib are the most advanced in clinical trials. Both have been investigated in randomized clinical trials in CLL patients, some of which have made direct comparisons with ibrutinib [16, 17].

Table 1. Irreversible and reversible Brutton kinase inhibitors approved or in clinical trials in chronic lymphocytic leukemia

\begin{tabular}{|c|l|l|l|l|l|}
\hline \multicolumn{1}{|c|}{ BTKI } & \multicolumn{1}{|c|}{ Binding } & $\begin{array}{c}\text { T1/2 } \\
\text { [hours] }\end{array}$ & IC50 [nM] & Dosing & Clinical trials in CLL \\
\hline Ibrutinib & $\begin{array}{l}\text { Covalent } \\
\text { irreversible } \\
\text { C481 }\end{array}$ & $4-8$ & 0.5 & $420 \mathrm{mg}$ & $\begin{array}{l}\text { NCT04771507 } \\
\text { NCT03513562 } \\
\text { NCT02912754 }\end{array}$ \\
\hline Acalabrutinib & $\begin{array}{l}\text { Covalent } \\
\text { irreversible } \\
\text { C481 }\end{array}$ & 0.9 & 5.1 & $100 \mathrm{mg}$ twice a day & $\begin{array}{l}\text { NCT04008706 } \\
\text { NCT04930536 }\end{array}$ \\
& $\begin{array}{l}\text { Covalent } \\
\text { Zanubrutinib } \\
\end{array}$ & $2-4$ & 0.5 & 160 or 320 mg twice a & NCT04116437 \\
& C481 & & & day & NCT04458610 \\
& & & & & NCT03824483 \\
& & & & & NCT04282018 \\
& & & & NCT04515238 \\
\hline
\end{tabular}




\begin{tabular}{|l|l|l|l|l|l|}
\hline & & & & & NCT03336333 \\
\hline Spebrutinib & $\begin{array}{l}\text { Covalent } \\
\text { irreversible } \\
\text { C481 }\end{array}$ & $8-24$ & $<0.5$ & $1000 \mathrm{mg}$ & NCT02031419 \\
\hline Tirabrutinib & $\begin{array}{l}\text { covalent } \\
\text { irreversible } \\
\text { C481 }\end{array}$ & NA & 5.6 & $80 \mathrm{mg}$ & $\begin{array}{l}\text { NCT03740529 } \\
\text { NCT03162536 }\end{array}$ \\
\hline Pirtobrutinib & $\begin{array}{l}\text { Non-covalent } \\
\text { reversible }\end{array}$ & NA & 0.85 & $200 \mathrm{mg}$ & $\begin{array}{l}\text { NCT05023980 } \\
\text { NCT04965493 } \\
\text { NCT05024045 } \\
\text { NCT04666038 }\end{array}$ \\
\hline Vecabrutinib & $\begin{array}{l}\text { Non-covalent } \\
\text { reversible }\end{array}$ & $6.6-8$ & 24 & $25 \mathrm{mg}$ escalated to & NCT03037645 \\
\hline Fenebrutinib & $\begin{array}{l}\text { Non-covalent } \\
\text { reversible }\end{array}$ & 2.2 & 0.91 & $200 \mathrm{mg}$ twice a day & NCT01991184 \\
\hline MK1026 & $\begin{array}{l}\text { Non-covalent } \\
\text { reversible }\end{array}$ & NA & 0.85 & $65-100 \mathrm{mg}$ & $\begin{array}{l}\text { NCT04728893 } \\
\text { NCT03162536 }\end{array}$ \\
\hline
\end{tabular}

More recently, novel agents continue to be developed for CLL, with the aim of reducing toxicity and improving efficacy. These agents have shown encouraging results in early clinical results; however, no long-term data is yet available. This review therefore summarizes the pharmacology, clinical efficacy, safety, dosing, drug-drug interactions of the treatment of CLL with BTKi, and discusses its further implications.

\section{Mechanism of action}

B-cell receptor (BCR) signaling is an essential component of the development and survival of normal and malignant B cells [18]. In a CLL-like mouse model, BTK deficiency significantly delayed development and reduced leukemia infiltration, but still resulted in the development of lymphogenesis. In vivo BTK inhibition abolished tumor formation, while BTK overexpression increased cancer incidence and overall mortality [19].

The BCR signaling pathway includes several elements, the most important of which is BTK. This kinase consists of several regions, including the pleckstrin homology (PH) domain, the Tec homology (TH) domain, the Src homology (SH3) domain, the SH2 domain and the C-terminal region with kinase activity. BCR signaling can be tonic or chronically activated. It is initiated by the antigen binding to the surface immunoglobulin, followed by autophosphorylation of the CD79A/CD79B heterodimer by kinases from Src family [20]. In CLL cells, constitutive phosphorylation of phospholipase C- $\gamma 2$ (PLC- $\gamma 2$ ), spleen tyrosine kinase (Syk), protein kinase C (PKC)- $\beta$, BTK and phosphoinositide 3 '-kinase (PI3K) lead resulted in the activation of the nuclear factor kappa $B$ $(\mathrm{NF}-\mathrm{kB})$ pathway [21]. This process may interact with microenvironmental stimuli and thus initiate the maintenance of survival, proliferation or migration of CLL cells $[6,11]$. Targeting the BCR pathway via the inhibition of BTK has evolved the treatment of some B-cell malignancies, including CLL. Most BTKIs target the ATP binding site of BTK, which contains cysteine (C481), known to target several irreversible inhibitors. C481 in BTK can act as a nucleophile and form a covalent bond with the inhibitor.

BTK inhibitors are the most advanced targeted drugs in B-cell lymphoid malignancies. Their characteristics are presented in Table 1 . The majority of currently approved BTKIs are irreversible inhibitors. Three of them, ibrutinib, acalabrutinib, and 
zanubrutinib, have been approved by the U.S. Food and Drug Administration (FDA) for the treatment of B cell neoplasms and graft-versus-host disease (GVHD).

These three approved BTKIs have been found to demonstrate certain similarities. All irreversibly covalently bind to cysteine 481 in the ATP binding pocket of BTK. Biochemical binding kinetics indicate that ibrutinib is the most potent BTKi of the three, followed by zanubrutinib and acalabrutinib, but differences in biochemical potency were partially obscured in cellular assays using human peripheral blood mononuclear cells or human white blood cells (all below $10 \mathrm{nM}$ ). Acalabrutinib had the lowest off-target ratio and the highest selectivity, followed by zanubrutinib and ibrutinib [22]. These differences in pharmacodynamics and pharmacokinetics may influence the dosage, efficacy and side effects of the inhibitors in clinical practice. Acalabrutinib had a shorter half-life than ibrutinib administered once daily, and the BTK load was found to be higher with twice daily dosing than with once daily dosing (95.3\% vs $87.6 \%)$, indicating that the drug requires twice daily dosing, i.e in 24 hours [23]. Moreover, acalabrutinib was found to have an inhibitory effect on epidermal growth factor receptor (EGFR), which can be associated with rash and severe diarrhea [24]. Also, ibrutinib can trigger TEC kinase, which contributes to platelet dysfunction and increases the risk of bleeding [25].

\section{Irreversible covalent BTK inhibitors}

\subsection{Ibrutnib}

Ibrutnib (PCYC-1102, Imbruvica ${ }^{\circledR}$, Pharmacyclics LLC, Sunnyvale, CA, USA) was discovered in 2007 as an irreversible inhibitor for BTK [26]. The drug was approved by the FDA in 2013 for the treatment of mantle cell lymphoma (MCL) and in 2014 for relapsed/refractory CLL. Subsequently, ibrutinib was approved for Waldenström's macroglobulinemia (WM), GVHD and marginal zone lymphoma (MZL). Ibrutinb binds to the cysteine 481 (C481) residue of BTK, irreversibly inhibiting phosphorylation of downstream kinases in the BCR signaling pathway and blocking B-cell activation. However, ibrutinib can also block other kinases, including EGFR, ErbB2, ITK and TEC [27]. Ibrutinib treatment can result in AEs such as bleeding and cardiac arrhythmia due to its off-target activity [28].

\subsubsection{Ibrutinib in relapsed and refractory CLL}

Several clinical studies with ibrutinib in monotherapy have been performed in patients with CLL [29]. An initial phase 1b/2 PCYC-1102 study and PCYC-1103 extension study included patients receiving single-agent ibrutinib in first-line or relapsed/refractory CLL/SLL. Ibrutinib was administered in a daily dose of 420 or $840 \mathrm{mg}$ until unacceptable toxicity or disease progression. The final analysis yielded similar results in overall response rate (ORR) between first-line patients (87\%) and relapsed/refractory (R/R) patients (89\%); however, the first-line group demonstrated higher complete response (CR), i.e. $35 \%$, than the R/R group (10\%) [29]. The estimated 7 -year PFS rates were $83 \%$ in the first-line group and $34 \%$ in $R / R$ patients. Forty-one patients had CLL progression including 11 with Richter's transformation. Median PFS was not reached (NR) with first-line ibrutinib. In relapsed/refractory CLL/SLL, patients with 17p deletion (del(17p)) demonstrated overall median progression free survival (PFS) of 52 months and 26 months. Estimated 7-year overall survival (OS) rates were $84 \%$ in previously untreated patients and $55 \%$ in $R / R$ patients. Most common grade $\geq 3$ adverse events (AE) were hypertension $(28 \%)$, pneumonia $(24 \%)$, and neutropenia $(18 \%)$. Importantly, grade $\geq 3$ AEs declined over time in most patients, excluding hypertension

The phase 3 RESONATE trial compared ibrutinib with ofatumumab in 391 patients with R/R CLL (Table 2). The median follow-up in this study was 65.3 months. Ibrutinib 
significantly improved both PFS and OS. Among the ibrutinib-treated patients, ORR was $91 \%$, including $11 \%$ CR. The median PFS was 44.1 months for the ibrutinib arm and 8.1 months for the ofatumumab arm $(\mathrm{p}<0.001)$. Patients receiving ibrutinib showed longer OS than those treated with ofatumumab (HR: 0.639; 95\% CI: 0.418-0.975). Ibrutinib was found to be relatively safe drug with a good toxicity profile. At a median follow-up of 41 months, hypertension was observed in $21 \%$ of patients treated with ibrutinib and atrial fibrillation in $12 \%$; in addition, grade 3 and higher AEs were found in $9 \%$ and $6 \%$, respectively. Ibrutinib was discontinued due to adverse events in $16 \%$ of patients [30]. The results of this study indicate that treatment with ibrutinib allowed for a greater improvement in disease symptoms and hematological parameters compared to ofatumumab and significantly improved the quality of life of patients with CLL/SLL. The long term effects of ibrutinib treatment among patients taking part in the RESONATE study [31] were published recently; this is the longest follow-up analysis for an oral target inhibitor in CLL (65.3 months median follow-up). Median PFS remained significantly longer in patients randomized to ibrutinib compared to ofatumumab (44.1 months vs 8.1 months). The benefit of PFS with ibrutinib was maintained in the high-risk population with del(17p), TP53 mutation, del (11q) and immunoglobulin heavy chain variable region $(I g V H)$ unmutated status.

Table 2. Phase 3 clinical trials of BTK inhibitors in relapsed/refractory chronic lymphocytic leukemia

\begin{tabular}{|c|c|c|c|c|c|c|}
\hline Study & Treatment & $\begin{array}{l}\text { Patients, } \\
\text { N }\end{array}$ & $\begin{array}{l}\text { Median } \\
\text { age } \\
\text { [years] }\end{array}$ & ORR (CR) & Median PFS & $\begin{array}{l}\text { Median } \\
\text { OS }\end{array}$ \\
\hline $\begin{array}{l}\text { Byrd et al.[30] } \\
\text { Munir et al. } \\
\text { [31](RESO- } \\
\text { NATE) }\end{array}$ & $\begin{array}{l}\text { Ibrutinib vs } \\
\text { Ofatumumab }\end{array}$ & $\begin{array}{l}195 \text { vs } \\
196\end{array}$ & 67 vs 67 & $\begin{array}{l}91 \%(21 \%) \\
\text { vs } 82 \% \\
(11 \%)\end{array}$ & $\begin{array}{l}44.1 \mathrm{~m} \text { vs } \\
8.1 \mathrm{~m}\end{array}$ & $\begin{array}{l}67.7 \mathrm{~m} \\
\mathrm{vs} \\
65.1 \mathrm{~m}\end{array}$ \\
\hline $\begin{array}{l}\text { Fraser et al. } \\
{[36] \text { (HELIOS) }}\end{array}$ & $\begin{array}{l}\text { Ibrutinib + BR vs } \\
\text { BR }\end{array}$ & $\begin{array}{l}289 \text { vs } \\
289\end{array}$ & $\begin{array}{ll}64 & \mathrm{vs} \\
63 & \end{array}$ & $\begin{array}{l}87 \%(38 \%) \\
\text { vs 66\% } \\
(8 \%)\end{array}$ & $\begin{array}{l}\text { NR vs } \\
13.3 \mathrm{~m} \\
p<0.0001\end{array}$ & $\begin{array}{l}\text { NR } \quad \text { vs } \\
\text { NR, } \\
p=0.0598\end{array}$ \\
\hline $\begin{array}{l}\text { Moreno et al. } \\
\text { [39](iLLUMI- } \\
\text { NATE) }\end{array}$ & $\begin{array}{l}\text { Ibrutinib vs } \\
\text { Chlorambucil + O }\end{array}$ & $\begin{array}{l}113 \text { vs } \\
116\end{array}$ & $\begin{array}{l}70 \text { vs } \\
72\end{array}$ & $\begin{array}{l}79 \%(19 \%) \\
\text { vs 31\% } \\
(8 \%)\end{array}$ & $\begin{array}{l}\text { NR vs } \\
19 \mathrm{~m}\end{array}$ & NA \\
\hline $\begin{array}{l}\text { Byrd et al. [48] } \\
\text { (ELEVATE RR) }\end{array}$ & $\begin{array}{l}\text { Acalabrutinib vs } \\
\text { Ibrutinib }\end{array}$ & $\begin{array}{l}268 \text { vs } \\
265\end{array}$ & NA & $\begin{array}{l}81.0 \%(\mathrm{NA}) \\
\text { vs } \\
77 \% \text { (NA) }\end{array}$ & $\begin{array}{l}38.4 \mathrm{vs} \\
38.4\end{array}$ & $\begin{array}{l}63 \% \text { vs } \\
73 \% \\
\text { at } 40,9 \mathrm{~m}\end{array}$ \\
\hline $\begin{array}{l}\text { Ghia et al. [47] } \\
\text { (ASCEND) }\end{array}$ & $\begin{array}{l}\text { Acalabrutinib } \\
\text { vs IR or BR }\end{array}$ & $\begin{array}{l}155 \text { vs } \\
155\end{array}$ & NA & $\begin{array}{l}81 \%(0 \%) v s \\
75 \%(1 \%)\end{array}$ & $\begin{array}{l}\text { NR vs } 16.5 \\
\mathrm{~m}\end{array}$ & $\begin{array}{l}4 \% \\
\text { vs } 91 \% \\
\text { at } 20 \mathrm{~m} \\
\end{array}$ \\
\hline $\begin{array}{l}\text { Hillmen et al. } \\
\text { [ 17] ALPINE }\end{array}$ & $\begin{array}{l}\text { Zanubrutinib vs } \\
\text { Ibrutinib }\end{array}$ & $\begin{array}{l}\text { Total } \\
415\end{array}$ & & $\begin{array}{l}76 \% \text { vs. } \\
64 \%\end{array}$ & $\begin{array}{l}95 \% \text { vs } \\
84 \%(\mathrm{HR} \\
0.40)\end{array}$ & $\begin{array}{l}97 \% \text { vs } \\
93 \% \text { at } 1 \mathrm{y}\end{array}$ \\
\hline
\end{tabular}


Abbreviations: BR- Bendamustine and rituximab, FCR- fluorouracil, cyclophosphamide and rituximab, IR - idelalisib + rituximab, $\mathrm{m}$ - months, $\mathrm{N}$ - number of patients, CR- complete remission, PFS- progression free survival, $\mathrm{R}-$ rituximab, NA- not available, NR- not reached, $\mathrm{O}$ - obinutuzumab, OS- overall survival, R- rituximab, yrs - years

Several studies have attempted to combine ibrutinib with other regimens such as rituximab, ofatumumab, venetoclax or rituximab and bendamustine (BR) in R/R CLL to improve efficacy [32-34]. The randomized trial of ibrutinib vs. ibrutinib with rituximab included 208 patients with CLL, 181 with recurrent CLL and 27 treatment-naïve with high-risk disease: (del)17p or TP53 mutation [35]. The addition of rituximab to ibrutinib in relapsed and untreated high-risk CLL patients did not improve PFS.

Elsewhere, the combination of ibrutinib with BR was found to be more effective than BR alone: the ibrutinib plus BR (87.2\%) group demonstrated a significantly higher ORR than the BR $(66.4 \%)$ group alone, with continuous improvement seen over time with the ibrutinib arm [37]. While the ibrutinib + BR arm also demonstrated longer PFS.

The three-year PFS was $70.2 \%$ of patients in the ibrutinib + BR arm but only $15.5 \%$ in the BR monotherapy arm [36]. Ibrutinib and ibrutinib + BR had similar PFS and OS results; however, it is not known whether the deeper responses observed for ibrutinib $+\mathrm{BR}$ will translate into improved OS and PFS [37].

\subsubsection{Ibrutinib in previously-untreated CLL}

In the RESONATE-2 study, 269 patients with untreated CLL patients 65 years or older without del (17p) were randomized to two arms: ibrutinib $420 \mathrm{mg}$ orally daily until disease progression or chlorambucil monotherapy (Table 3) [38] With a median follow-up of 60 months, PFS was 70\% for ibrutinib vs 12\% for chlorambucil (HR [95\% CI]: 0.146 [0.098-0.218]). As a secondary endpoint, ibrutinib also improved 5-year OS compared to chlorambucil ( $83 \%$ vs. $68 \%$; HR $0.45,95 \% \mathrm{CI}=0.266-0.761$ ). The benefits obtained from ibrutinib treatment were also observed in patients with TP53 mutation, 11q deletion, and/or unmutated IGHV) (PFS: HR [95\% CI]: 0.083 [0.047-0.145]; OS: HR [95\% CI]: 0.366 [0.181-0.736]. ORR was 92\% with ibrutinib (CR, 30\%; 11\% at primary analysis). Most common grade $\geq 3$ AEs included neutropenia (13\%), anemia (7\%), pneumonia (12\%), hypertension $(8 \%)$, and hyponatremia $(6 \%)$.

Subsequent studies compared ibrutinib, alone or in combination with CD20 monoclonal antibodies, with standard immunochemotherapy regimens (Table 3). In the iLLUMINATE study, previously untreated, patients aged 65 years or older and younger patients with coexisting comorbidities were randomized to receive either obinutuzumab + ibrutinib or obinutuzumab + chlorambucil [39]. Median PFS was significantly longer in the obinutuzumab + ibrutinib arm compared to the obinutuzumab + chlorambucil arm (NR vs. 19 months; HR 0.23, 95\% CI =0.15-0.37, $\mathrm{p}<0.001$ ). In a subgroup analysis, patients with high-risk characteristics of CLL (del17p, del11q, TP53 mutations, or unmutated IgHV) also showed significant improvement in PFS in the ibrutinib arm compared to immunochemotherapy (median NR vs. 14.7 months; $\mathrm{p}<0.001$ ). Elsewhere (A041202), 547 elderly patients ( $\geq 65$ years of age) with previously untreated CLL were randomized to receive ibrutinib alone, ibrutinib combined with rituximab or BR [40]. The 2-year PFS was higher for both ibrutinib alone (87\%) and for ibrutinib + rituximab (88\%) compared to BR $(74 \%)$ ( $p<0.001$ for both comparisons). The ORR values for ibrutinib, ibrutinib and rituximab, and $\mathrm{BR}$ were $93 \%, 94 \%$, and $81 \%$, respectively. 
Table 3. Phase 3 clinical trials of BTK inhibitors in treatment naïve CLL

\begin{tabular}{|c|c|c|c|c|c|c|}
\hline Study & Treatment & $\mathbf{N}$ & $\begin{array}{l}\text { Median } \\
\text { age } \\
\text { [years] }\end{array}$ & $\begin{array}{l}\text { ORR (CR) } \\
\text { rate }\end{array}$ & Median PFS & Median OS \\
\hline $\begin{array}{l}\text { Burger at al. } \\
{[9,38]} \\
\text { RESONATE } 2\end{array}$ & $\begin{array}{l}\text { Ibrutinib vs } \\
\text { Chlorambucil }\end{array}$ & $\begin{array}{l}136 \text { vs } \\
133\end{array}$ & 73 vs 72 & $\begin{array}{l}86 \%(4 \%) \text { vs. } \\
35 \%(2 \%)\end{array}$ & $\begin{array}{l}\text { NR vs } 18.9 \\
\mathrm{~m} ; p<0.001\end{array}$ & 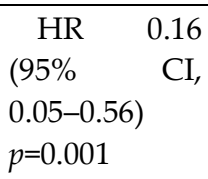 \\
\hline $\begin{array}{l}\text { Fraser et al. } \\
\text { [36] (HELIOS) }\end{array}$ & $\begin{array}{l}\text { Ibrutinib + BR } \\
\text { vs BR }\end{array}$ & $\begin{array}{l}289 \text { vs } \\
289\end{array}$ & $\begin{array}{ll}64 \mathrm{vs} \\
63\end{array}$ & $\begin{array}{l}87 \%(38 \%) \text { vs } \\
66 \%(8 \%)\end{array}$ & $\begin{array}{l}\text { NR versus } \\
13.3 \mathrm{~m} \\
p<0.0001\end{array}$ & $\begin{array}{l}\text { NR vs } \\
\text { NR, } \\
p=0.0598\end{array}$ \\
\hline $\begin{array}{l}\text { Burger et al. } \\
{[35]}\end{array}$ & $\begin{array}{l}\text { Ibrutinib vs } \\
\text { Ibrutinib + R }\end{array}$ & $\begin{array}{l}104 \mathrm{vs} \\
104\end{array}$ & $\begin{array}{l}65 \mathrm{vs} \\
65\end{array}$ & $\begin{array}{l}92 \%(30 \%) \text { vs } \\
37 \%(11 \%)\end{array}$ & $\begin{array}{l}86 \% \text { vs } \\
86.9 \% \text { at } 36 \mathrm{~m}\end{array}$ & $\begin{array}{l}92 \% \text { vs } \\
89 \% \text { at } 3-y\end{array}$ \\
\hline $\begin{array}{l}\text { Moreno et al. } \\
\text { [39] } \\
\text { (iLLUMINATE) }\end{array}$ & $\begin{array}{l}\text { Ibrutinib vs } \\
\text { Chlorambucil + } \\
\mathrm{O}\end{array}$ & $\begin{array}{l}113 \text { vs } \\
116\end{array}$ & $\begin{array}{l}70 \mathrm{vs} \\
72\end{array}$ & $\begin{array}{l}79 \%(19 \%) \\
\text { vs } \\
31 \%(8 \%)\end{array}$ & $\begin{array}{l}\text { NR vs } \\
19 \mathrm{~m} ;\end{array}$ & NA \\
\hline $\begin{array}{l}\text { Woyach et al. } \\
\text { [40] } \\
\text { (A041202) }\end{array}$ & $\begin{array}{l}\text { BR vs Ibrutinib } \\
\text { vs Ibrutinib + } \\
\text { R. }\end{array}$ & $\begin{array}{ll}183 & \text { vs } \\
182 & \text { vs } \\
182 & \end{array}$ & $\begin{array}{l}70 \mathrm{vs} \\
71 \mathrm{vs} \\
71\end{array}$ & $\begin{array}{l}81 \% \text { vs } 93 \% \\
\text { vs } 94 \%\end{array}$ & $\begin{array}{l}74 \% \text { vs } 87 \% \\
\text { vs } 88 \% \text { at } \\
2 \text { yrs }\end{array}$ & $\begin{array}{l}95 \% \text { vs } \\
90 \% \text { vs } \\
94 \% \text { at } 2 \text { y }\end{array}$ \\
\hline $\begin{array}{l}\text { Shanefelt et al. } \\
\text { [41] } \\
\text { (ECOG 1912) }\end{array}$ & $\begin{array}{l}\text { Ibrutinib vs } \\
\text { FCR }\end{array}$ & $\begin{array}{ll}354 & \text { vs } \\
175 & \end{array}$ & $\begin{array}{l}56,7 \\
\text { vs } 56,7\end{array}$ & $\begin{array}{l}95.8 \% \\
(17.2 \%) \quad \text { vs } \\
81.1 \% \\
(30.3 \%)\end{array}$ & $\begin{array}{l}89.4 \text { vs } 72.9 \% \\
\text { at 3-yrs }\end{array}$ & $\begin{array}{l}98,8 \% \\
\text { vs } 91.5 \% \\
\text { at 3-yrs }\end{array}$ \\
\hline $\begin{array}{l}\text { Tam et al. } \\
{[52](\text { SEQUOIA) }}\end{array}$ & $\begin{array}{l}\text { Zanubrutinib vs } \\
\text { BR }\end{array}$ & $\begin{array}{l}241 \mathrm{vs} \\
238\end{array}$ & $\begin{array}{l}70 \mathrm{vs} \\
70\end{array}$ & $\begin{array}{l}94.6 \%(6.6 \%) \\
\text { vs } \\
85.3 \%(15.1 \%)\end{array}$ & $\begin{array}{l}\text { At } 2 \text { y } 85.5 \% \\
\text { vs } 69.5 \%\end{array}$ & NA \\
\hline $\begin{array}{l}\text { Sharman et al. } \\
\text { [46] (ELEVATE } \\
\text { TN) }\end{array}$ & $\begin{array}{l}\text { Acalalabrutinib } \\
\text { vs Acalalabru- } \\
\text { tinib + O vs } \\
\text { Chlorambucil + } \\
\text { O }\end{array}$ & $\begin{array}{l}179 \text { vs } \\
179 \text { vs } \\
177\end{array}$ & NA & $\begin{array}{l}94 \%(1 \%) \\
\text { vs } 95 \%(14 \%) \\
\text { vs } 89 \%(5 \%)\end{array}$ & $\begin{array}{l}\text { NR vs } \\
\text { NR vs } \\
22.6 \mathrm{~m}\end{array}$ & $\begin{array}{l}95 \% \\
\text { vs } 95 \% \\
\text { vs } 92 \% \text { at } 2 y\end{array}$ \\
\hline
\end{tabular}

Abbreviations: BR - Bendamustine and rituximab, CR- complete remission, FCR- fluorouracil, cyclophosphamide and rituximab, $\mathrm{m}$ - months, HR - hazard ratio, N- number of patients, NA- not available, NR- not reached, O - oninutuzumab, ORR- overall response rate, OS - overall survival, PFS - progression free survival, R- rituximab, FCR - rituximab, fludarabine, cyclophosphamide, y - years.

Among older patients with untreated CLL, treatment with ibrutinib, alone or in combination, offered better PFS compared to BR. However, no significant differences in ORR were observed between those three study groups, as counted after a median follow-up of 38 months. Shanefelt et al compared the efficacy and safety of ibrutinib and rituximab with standard chemoimmunotherapy with fludarabine, cyclophosphamide and rituximab (FCR) in patients with previously-untreated CLL, aged 70 years or younger (E1912 study) [41]. Patients received ibrutinib $420 \mathrm{mg}$ orally once daily until 
disease progression or toxicity and rituximab once every 28 days for six doses. Patients with del (17p) were excluded due to the historically poor response of this population to FCR. The primary endpoint was PFS, and OS was a secondary endpoint. A total of 529 patients were randomized in this study. More patients achieved 3-year PFS with ibrutinib and rituximab compared to FCR $(89.4 \%$ vs $72.9 \%$; $<<0.001)$. Ibrutinib combined with rituximab yielded better 3 -year OS than FCR $(98.8 \%$ vs $91.5 \%$; $p<0.001)$. Both arms demonstrated similar rates of grade $\geq 3$ AEs $(80.1 \%$ vs $79.7 \%)$.

\subsection{Acalabrutinib}

Acalabrutinib (ACP-196, Calquence®, AstraZeneca Pharmaceuticals LP) is a novel second-generation oral, potent, highly-selective, covalent BTKi, designed by Acerta Pharma. Acalabrutinib has a reactive butinamide group that can covalently bind to C481 in BTK. The structural properties of this compound differ from ibrutinib, thus reducing off-target binding; for example, the EGFR and ITK are not inhibited by acalabrutinib.

In the phase $1 / 2$ trial, acalabrutinib was evaluated in 61 patients with relapsed/refractory CLL (Table 2). The patients received acalabrutinib at a dose of 100 to $400 \mathrm{mg}$ once daily in the dose-escalation phase (Phase 1) and $100 \mathrm{mg}$ twice daily in the dose-escalation part (Phase 2) [42]. The patients had received a median of three lines of previous treatments for CLL. Among high risk patients, 31\% had chromosome 17p13.1 deletion and $75 \%$ had unmutated IGVH. At a median follow-up of 14.3 months, the OR rate was 95\%, including 85\% with a partial response (PR) and 10\% with a PR with lymphocytosis. All patients $(100 \%)$ with chromosome 17 p13.1 deletion, responded to the treatment. The most common AEs were headache (43\%), diarrhea (39\%), and increased weight $(26 \%)$, and most were of grade 1 or 2 .

The results of the updated and expanded phase 2 study confirmed the efficacy and long-term safety of acalabrutinib in previously-treated patients with CLL from the phase $1 \mathrm{~b} / 2$ study. In a recent report, 134 patients were treated $100 \mathrm{mg}$ acalabrutinib twice daily for a median of 41 months [43]; the ORR was $94 \%$ with similar responses demonstrated by patients with $\operatorname{del}(11)(\mathrm{q} 22.3)$, del(17)(p13.1), complex karyotype, or IGVH mutation status. Median PFS was not reached (NR) and estimated 45-month PFS was 62\%. The most commonly seen AEs were diarrhea (52\%) and headache (51\%). All grades of atrial fibrillation were observed in $7 \%$ of patients and major bleeding AEs in $5 \%$. Importantly, $56 \%$ of patients remain on treatment. The most common reasons for discontinuing therapy was progressive disease (21\%) and AEs (11\%).

Acalabrutinib was also evaluated in a group of 99 treatment-naïve CLL patients, in a single-arm phase 1/2 trial (ACE-CL-001) [44]. Among the recruited patients, 57 (62\%) had unmutated $I G V H$, and $12(18 \%)$ had TP53 mutation or deletion. Acalabrutinib was given orally $200 \mathrm{mg}$ once daily, or $100 \mathrm{mg}$ twice daily until progression or unacceptable toxicity. After a median follow-up of 53 months, 14 patients had discontinued treatment and 85 remained on treatment. Discontinuation was due to AEs in six patients, and disease progression in three. The OR rate was 97\%, including 90\% PR and 7\% CR. The four-year duration of response (DOR) was $97 \%$ and median DOR was not reached. Serious AEs were reported in 38 patients (38\%). Grade $\geq 3$ events of special interest were infection (15\%), hypertension (11\%), bleeding events (3\%), and atrial fibrillation (2\%).

In a phase $1 \mathrm{~b} / 2$ study Woyach et al. assessed combined acalabrutinib + obinutuzumab therapy in 19 treatment-naïve and $26 \mathrm{R} / \mathrm{R}$ CLL patients [45]. Acalabrutinib was administered at a dose of $100 \mathrm{mg}$ twice daily until progression, and obinutuzumab was dosed sequentially from 100 to $1000 \mathrm{mg} /$ day for up to six cycles. ORR was $95 \%$ in treatment-naïve patients and $92 \%$ in R/R patients, with a CR achieved in 32 and $8 \%$ of patients. In addition, $94 \%$ previously untreated and $88 \% \mathrm{R} / \mathrm{R}$ patients were progression free at three years. Grade 3/4 AEs was reported in $71 \%$ of patients.

The phase 3 ELEVATE TN (NCT02475681) study evaluated acalabrutinib treatment in previously-untreated CLL patients (Table 3) [46]. A total of 535 patients were randomized to acalabrutinib alone, acalabrutinib + obinutuzumab or chlorambucil + 
obinutuzumab arms. Of the patients, 63\% had unmutated IGHV and 9\% del(17p). Patients were randomized to receive acalabrutinib, acalabrutinib/obinutuzumab, or chlorambucil/obinutuzumab. Patients randomized to the acalabrutinib arms received acalabrutinib $100 \mathrm{mg}$ orally twice daily until disease progression or intolerable toxicity. Patients treated with acalabrutinib + obinutuzumab had significantly longer PFS compared to chlorambucil + obinutuzumab (median NR vs. 22.6 months; $\mathrm{p}<0.0001$ ). Acalabrutinib monotherapy also resulted in a significant increase in PFS compared to chlorambucil + obinutuzumab (median NR vs. 22.6 months; p <0.0001). Acalibrutinib + obinutuzumab significantly prolonged PFS compared to acalibrutinib alone (median NR vs. 22.6 months; $\mathrm{p}<0.0001$ ). Acalabrutinib monotherapy also significantly prolonged PFS compared to chlorambucil + obinutuzumab (median NR vs. 22.6 months; $\mathrm{p}<0.0001$ ). Median OS was NR in all groups. The most common grade 3 or higher AE in all three groups was neutropenia: $30 \%$ in the acalabrutinib + obinutuzumab group, $9 \%$ in the acalabrutinib group, and $41 \%$ in the obinutuzumab + chlorambucil group. Infections (grade 3 or higher) were noted in $21 \%$ of patients in the acalabrutinib + obinutuzumab arm, $14 \%$ in the acalabrutinib monotherapy arm, and $8 \%$ in the obinutuzumab + chlorambucil arm. At four-year follow up (median 46.9 months) the acalabrutinib + obinutuzumab arm demonstrated significantly higher ORR (96.1\%) and CR (26.8\%/) than the obinutuzumab + chlorambucil arm (ORR 82.5\%; CR 12.4\%/) (P<0.0001). The acalabrutinib monotherapy arm yielded an ORR of $89.9 \%(\mathrm{P}=0.035$ vs obinutuzumab + chlorambucil). The median PFS was NR for acalabrutinib + obinutuzumab and acalabrutinib alone, and 27.8 months for chlorambucil + obinutuzumab (both $\mathrm{P}<0.0001$ ). Estimated 4-year PFS rates were $87 \%$ for acalabrutinib + obinutuzumab, $78 \%$ for acalabrutinib, and $25 \%$ for chlorambucil + obinutuzumab; however, median OS was NR in all three groups, with estimated 4 -year OS rates of $93 \%, 88 \%$, and $88 \%$ respectively. Treatment discontinuation rates were $25.1 \%$ in acalabrutinib + obinutuzumab, $30.7 \%$ in acalabrutinib alone and $22.6 \%$ in chlorambucil + obinutuzumab. AEs were the most common reasons for treatment discontinuation $(12.8 \%, 12.3 \%, 14.7 \%$, respectively). Progressive disease was observed in $4.5 \%, 7.8 \%$ and $1.7 \%$, respectively.

In the ASCEND multicenter, randomized, open-label phase 3 study, $310 \mathrm{R} / \mathrm{R}$ patients were randomized to acalabrutinib monotherapy or the investigator's choice: idelalisib-rituximab (IR) or bendamustine with rituximab (BR) (Table 2). [47]. In this trial $78 \%$ of patients had unmutated IGHV, 16\% had del (17p) and $24 \%$ had a mutated TP53 gene. The ORR was similar in both arms, including $81 \%$ for the acalabrutinib arm and $75 \%$ for the investigator's choice arm $(\mathrm{p}=0.22)$. However, at a median follow-up of 16.1 months, acalabrutinib had a significantly higher PFS (83\%) than the investigator's choice arm (56\%). Acalabrutinib was more effective across all clinical subgroups with regard to age, sex, ECOG, Rai staging, bulky disease, number of prior therapies, TP53 disruption, IGHV status, and complex karyotype. The DOR was not reached with the acalabrutinib arm, and was 13.6 months with the investigator's choice arm. Neither arm reached median OS, with rates exceeding 90\%. Grade 3/4 AEs occurred in $45 \%$ of patients on acalabrutinib vs. $86 \%$ on IR and $43 \%$ on BR. The most common high grade AEs on acalabrutinib were neutropenia, $16 \%$ (vs. $40 \%$ on I-R and $31 \%$ on BR), anemia, $12 \%$ (vs. $7 \%$ on IR and $9 \%$ on BR), pneumonia, $5 \%$ (vs. $9 \%$ on IR and $3 \%$ on BR). Atrial fibrillation (AF) was diagnosed in 5\% patients on acalabrutinib and in 3\% in the investigator's choice arm. Bleeding of any grade occurred in 26\% (acalabrutinib) and $7 \%$ of patients (investigator's choice). The ASCEND study is an important study as it is one of the first to compare two different small molecule inhibitors (idelalisib and acalabrutinib) in CLL.

In the third phase 3 trial (ELEVATE RR) acalabrutinib was compared with ibrutinib in 533 patients with R/R CLL(Table 2) [48]. This is the first direct comparison of thre less-selective BTK inhibitor ibrutinib with the more-selective inhibitor BTK acalabrutinib in CLL. In this study, patients with confirmed del(17) or del(11) received oral acalabrutinib $100 \mathrm{mg}$ twice daily or ibrutinib $420 \mathrm{mg}$ once daily until progression or unacceptable toxicity. At the time of analysis, 124 (46.3\%) patients treated with acalabrutinib and 109 (41.1\%) patients receiving ibrutinib were on treatment. After a median follow-up of 40.9 
months, both groups demonstrated similar PFS (median 38.4 months in both arms). However, the incidence of all-grade atrial fibrillation/atrial flutter was significantly lower with acalabrutinib (9.4\%) versus ibrutinib $(16.0 \% ; \mathrm{p}=0.02)$. Grade 3 or higher infections were similar (30.8\% vs 30.0\%) and Richter transformations (3.8\% vs $4.9 \%$ ) were comparable between groups. Median OS was not reached in either arm, with $63(23.5 \%)$ deaths recorded in the acalabrutinib arm and $73(27.5 \%)$ in the ibrutinib arm. In addition, the rate of treatment discontinuations due to adverse events was $14.7 \%$ in the acalabrutinib arm and $21.3 \%$ in the ibrutinib arm. To summarize, acalabrutinib treatment demonstrated non-inferior PFS with fewer cardiovascular adverse events compared to ibrutinib in pretreated, high risk CLL patients.

Sheng et al. compared acalabrutinib + obinutuzumab, ibrutinib + obinutuzumab and venetoclax + obinutuzumab in untreated CLL using a network meta-analysis from three trials [49]. In this analysis of 1017 patients, the acalabrutinib + obinutuzumab group demonstrated longer PFS compared with ibrutinib + obinutuzumab (HR:0.43, p=0.02) and venetoclax + obinutuzumab (HR:0.30, p<0.001). Sensitivity analysis also found acalabrutinib + obinutuzumab to have better PFS than ibrutinib + obinutuzumab (HR:0.46, p=0.04) and venetoclax + obinutuzumab (HR:0.34, $\mathrm{p}=0.002$ ). The investigator assessment found acalabrutinib + obinutuzumab to have the highest probability of obtaining the longest PFS (98.0\%). However, this regimen offered no survival advantage compared to ibrutinib + obinutuzumab (HR:0.51, $\mathrm{p}=0.21$ ) or venetoclax + obinutuzumab (HR:0.38, $\mathrm{p}=0.07$ ). In addition, no significant difference in AEs analysis was observed; however, prospective clinical trials comparing these regimens are needed to confirm this observation.

Acalabrutinib was granted accelerated approval by the U.S. FDA in 2017 for the treatment of patients with mantle cell lymphoma (MCL) who have received at least one prior therapy. In November 2019, acalabrutinib was also approved for the treatment of adult patients with CLL/SLL on the basis of two phase 3 clinical trials.

\subsection{Zanubrutinib}

Zanubrutinib (BGB-3111, Brukinsa ${ }^{\circledR}$, BeiGene USA, Inc., San Mateo, CA, USA) is a next-generation irreversible inhibitor of BTK developed by BeiGene in 2012 for the treatment of B-cell malignancies [50]. It was designed to maximize BTK occupancy and minimize off-target inhibition of TEC- and EGFR-family kinases. Zanubrutinib demonstrates greater selectivity than ibrutinib for BTK compared to other receptor tyrosine kinases, which may result in a lower incidence of off-target toxicities and reduced severity $[51,52]$. Moreover, zanubrutinib is similar to acalabrutinib, with less activity on TEC and ITK [53]. Like ibrutinib, zanubrutinib forms $\mathrm{H}$ bonds with the residues of the $\mathrm{E} 475$ and M477 regions. The drug induces beneficial changes in the immune microenvironment by reducing the level of checkpoint molecules on suppressor cells and adhesion/homing receptors on B-cells [54].

In a phase $1 / 2$ study, Tam et al. evaluated 78 patients with CLL/SLL treated with zanubrutinib monotherapy [55]. After a median follow-up of 13.7 months, ORR was 96.2\% (75/78), with two patients (2.6\%) achieving CR and 63 (80.8\%) PR. In approximately $20 \%$ of patients, zanubrutinib showed off-target effects, such as diarrhea and rash (all grade 1 or 2 AEs). Subsequently, updated safety and efficacy data, with a median follow-up of 25.1 months, were reported in a larger cohort of CLL/SLL patients [56]. The patients were treated with zanubrutinib at doses ranging from $40 \mathrm{mg}$ once daily to the final phase 2 dose of $160 \mathrm{mg}$ twice daily or $320 \mathrm{mg}$ once daily, until disease progression or unacceptable toxicity. The cohort included 120 efficacy-evaluable patients, including 22 treatment-naïve and $98 \mathrm{R} / \mathrm{R}$ patients. ORR was $97 \%$ with $14 \% \mathrm{CR}$ or CR with incomplete bone marrow recovery (CRi). The PFS rate was $97 \%$ at one year and $89 \%$ at two years; both values were similar in the treatment-naïve and $R / R$ patients. The most common AEs of any grade were contusion (46\%), upper respiratory tract infection (39\%), diarrhea $(30 \%)$, cough $(28 \%)$, headache $(23 \%)$, fatigue $(20 \%)$, urinary tract infection $(17 \%)$, back 
pain $(17 \%)$, rash $(17 \%)$, nausea $(16 \%)$, and neutropenia $(16 \%)$. During the follow-up treatment, discontinuation was seen in $21 / 122$ patients (17\%) mainly due to disease progression (13 patients) and AEs (four patients). Major hemorrhage was observed in $2 \%$ of patients and bleeding in $57 \%$. Atrial fibrillation or flutter was observed in three $(2.8 \%)$.

The efficacy and safety of zanubrutinib were reported in patients with treatment-naïve CLL/SLL with del(17p): Arm C of the SEQUOIA (BGB-3111-304) trial. [57]. In this open-label, global, multicenter, phase 3 study, 109 previously-untreated patients were treated with zanubrutinib at a dose of $160 \mathrm{mg}$ twice daily with a median follow-up of 18.2 months (range, 5.0-26.3). At the time of writing, 97 patients $(89.0 \%)$ were on treatment with zanubrutinib. ORR was $94.5 \%$ including $3.7 \%$ CR or CRI. Estimated 18-month PFS was 88.6\% and OS 95.1\%. Most common AEs included infections (64.2\%), bleeding $(47.7 \% ; 5.5 \%$ grade $\geq 3$ or serious), headache $(8.3 \%)$, hypertension $(8.3 \%)$, and myalgia (4.6\%).

Recently, interim results for the phase 3 SEQUOIA arms A and B (BGB-3111-304; NCT03336333) global registrational trial, evaluated the efficacy and safety of zanubrutinib vs BR in previously untreated patients with CLL, were reported (Table 3)[52]. Patients without del(17p) received zanubrutinib $160 \mathrm{mg}$ twice daily until disease progression or unacceptable toxicity or BR at the standard doses. ORR for zanubrutinib was $94.6 \%$ for zanubrutinib vs $85.3 \%$ for BR and CR rate $6.6 \%$ vs $15.1 \%$, respactively. At a median follow-up of 26.2 months PFS was longer with zanubrutinib vs BR (HR 0.42, 95\% CI 0.28-0.63, 1-sided and 2-sided $P<0.0001)$. Estimated 2-year PFS was $85.5 \%$ for zanubrutinib vs $69.5 \%$ for BR and 2-year OS $94.3 \%$ vs $94.6 \%$, respectively. Estimated 24-month OS for zanubrutinib vs BR was 94.3\% (95\% CI 90.4\%-96.7\%) and $94.6 \%$ (95\% CI $90.6 \%-96.9 \%)$. Zanubrutinib was generally well tolerated, with low rates of atrial fibrillation.

A phase 3 ALPINE (BGB-3111-305) study was designed to compare zanubrutinib monotherapy with ibrutinib in patients with R/R CLL(Table 2) [17,58]. Endpoints include safety, PFS, duration of response and OS. An interim analysis from the ALPINE study of zanubrutinib vs. ibrutinib in patients with R/R CLL/SLL were recently presented in abstract form [17]. Patients were randomized to receive zanubrutinib $160 \mathrm{mg}$ twice daily or ibrutinib 420 mg once daily; randomization took place between 5 Nov 2018 and 20 Dec 2019. Both drugs were given until disease progression. At a median follow-up of 15 mo, ORR was significantly higher with zanubrutinib $(78.3 \%)$ than ibrutinib $(62.5 \%, \mathrm{P}=0.0006)$ In the with zanubrutinib group, higher ORR scores were observed in patients with del11q (83.6\% vs 69.1\%) and del17p (83.3\% vs 53.8\%). Overall 12-months PFS was higher in the zanubrutinib group $(94.9 \%)$ than the ibrutinib group $(84.0 \%)$, with respective OS rates of $97.0 \%$ and $92.7 \%$. In addition, compared to ibrutinib, the zanubrutinib group demonstrated significantly lower rate of AF/flutter (2.5\% vs. $10.1 \%)(p=0.0014)$, a lower rate of major bleeding (2.9\% vs. 3.9\%), and lower rates of AEs leading to discontinuation (7.8\% vs. $13.0 \%)$. Furthermore, zanubrutinib demonstrated a lower death rate $(3.9 \%$ vs. $5.8 \%$ ), higher chance of neutropenia $(28.4 \%$ vs $21.7 \%)$, and lower rate of grade $\geq 3$ infections (12.7\% vs $17.9 \%)$. A phase 2 study evaluating the safety and efficacy of zanubrutinib in ibrutinib-intolerant CLL patients is ongoing (NCT04116437 trial).

Recently, zanubrutinib combined with obinutuzumab and venetoclax (BOVen) was tested as an initial therapy for 39 treatment naïve SLL/SLL in phase 2 trial [59]. The aim of the study was to increase the rates of undetectable minimal residual disease (MRD), and limit treatment duration. Zanubrutinib was given at a dose of $160 \mathrm{mg}$ twice per day continuously, obinutuzumab at $1000 \mathrm{mg}$ i.v. on day 1 [split over day 1 with $100 \mathrm{mg}$ and day 2 with $900 \mathrm{mg}$ ) day 8, and day 15 of cycle 1, and only on day 1 of cycles 2-8; and oral venetoclax ramp up to $400 \mathrm{mg}$ per day starting in cycle 3 on day 1) and discontinued after 8-24 cycles if undetectable minimal residual disease (MRD) was achieved in the peripheral blood and bone marrow. Among 39 included patients, 28 (72\%) had unmutated IGVH and five (13\%) had del (17p) or TP53 mutation. After a median follow-up of 25.8 months, undetectable MRD was identified in both blood and bone marrow in 33 (89\%) of 
37 patients and therapy was discontinued after a median of ten cycles. After median treatment of 15.8 months, 31 (94\%) of 33 patients had undetectable MRD. The most common AEs of all grades were thrombocytopenia (59\%), fatigue (54\%), neutropenia $(51 \%)$, and bruising $(51 \%)$. The only grade 3 or worse AE was neutropenia, observed in $18 \%$ of the patients. These data underline the need for further evaluation of BOVen in CLL patients [60]. Zanubrutinib has received approval by the FDA for the treatment of Waldenstrom macroglobulinemia (WM), R/R MCL and marginal zone lymphoma.

\subsection{Other irreversible BTK inhibitors}

Several other irreversible BTKis have recently been developed and are under clinical investigation in lymphoid malignancies and autoimmune disorders. These include pebrutinib, evobrutinib, olmutinib, tirabrutinib, elsubrutinib (ABBV-105), and tolebrutinib (SAR 442168).

\subsubsection{Spebrutinib}

Similar to ibrutinib, spebrutinib (CC-292) inhibits BTK activity by binding covalently with high affinity to the same cysteine 481 in BTK [61,62]. In preclinical studies, spebrutinib blocked BCR-dependent B-cell activation. [63]. In a first-in-human study performed in healthy volunteers, spebrutinib led to near-complete BTK occupancy for 8-24 h (Table 2). Spebrutinibat doses up to $1000 \mathrm{mg} /$ day were investigated in a phase 1 study in 84 patients with R/R CLL/SLL [64]. The patients included $21.4 \%$ with del(11q), $23.8 \%$ with del(17p), and 53.6\% with unmutated IGVH. CC-292 was well tolerated, with two patients experiencing grade 4 thrombocytopenia, one patient with grade 3 drug-related pneumonitis, one patient with grade 3 reversible mental-status changes. Common non-hematologic AEs of any grade were diarrhea $(68 \%)$, fatigue $(45 \%)$, nausea $(35 \%)$, cough $(27 \%)$, pyrexia $(27 \%)$, and headache $(25 \%)$. The median response duration was 11.0 months for the $750 \mathrm{mg}$ once daily group and 5.6 months for the $1000 \mathrm{mg}$ once daily, while this value was not yet reached for the $375 \mathrm{mg}$ twice daily and $500 \mathrm{mg}$ twice daily groups. This study indicates that spebrutinib was well tolerated and resulted in dose-dependent responses in R/R CLL/SLL patients, including those with high-risk cytogenetics. However, its clinical activity was lower than that observed in patients with ibrutinib or acalabrutinib.

\subsubsection{Evobrutinib}

Evobrutinib (A18, M2951) is an orally administered, highly selective, covalent BTK inhibitor [65]. It inhibits B-cell activation and cytokine release, and the activation, differentiation and polarization of M1 macrophages evobrutinib has greater BTK selectivity than ibrutinib. The drug has a good kinome selectivity and an acceptable preclinical pharmacokinetic/pharmacodynamic profile. It is currently being evaluated in clinical studies for treatment of various immunological diseases, including multiple sclerosis [66]. In a phase 1, double-blind, dose-escalation study in healthy participants, evobrutinib was given at doses of $25,50,100,200,350$, or $500 \mathrm{mg}$ or placebo as a single dose, or as 25,75 , or $200 \mathrm{mg}$ or placebo once daily for 14 days [67]. In this study, full BTK occupancy was achieved with $25 \mathrm{mg}$ evobrutinib after multiple daily dosing. Treatment-emergent AEs were observed in $25 \%$ volunteers after single-dosing and in $48.1 \%$ after multiple-dosing; these were mild in most participants without dose-dependency. The drug is currently under investigation as a treatment of multiple sclerosis [68]. The results achieved to date indicate that evobrutinib has the potential to become a valuable treatment option for patients with multiple sclerosis and possible also for those with other autoimmune disorders or B-cell malignancies, including CLL. 
Tirabrutinib (ONO/GS-4059, Velexbru®) is another very potent and specific BTKi targeting BTK C481. It demonstrates greater selectivity than ibrutinib. The drug demonstrated potent activity in patients with CLL/SLL. Walter et al. report the results of an initial phase 1 study involving 90 RR patients with various B-cell malignancies [69]. In the CLL group, 96\% (24/25) of patients achieved objective responses within the first three months of therapy. Elsewhere, a Japanese study examined its safety, efficacy, pharmacokinetics, pharmacodynamics and prognostic biomarkers in patients with R/R primary central nervous system lymphoma (PCNSL) [70]. The most common AE was found to be mild diarrhea, occurring in $18 \%$ of the cases. In the CLL cohort, $14.3 \%$ of patients experienced drug-related grade 3 or $4 \mathrm{AE}$, with the most common being hematological toxicity. Further studies of tirarutinib with other targeted drugs are ongoing [71].

\subsubsection{Elsubrutinib}

Elsubrutinib (ABBV-105, Abbvie) is an irreversible, highly-selective, and potent BTKi [72]. This agent demonstrates superior kinome selectivity and has demonstrated potency in BCR, Fc receptor, and TLR-9-dependent cellular assays. In a preclinical study, BTK occupancy in disease models correlated with in vivo efficacy. A phase 2 trial to investigate the safety and efficacy of ABBV-105 in rheumatoid arthritis (NCT03682705) and systemic lupus erythematosus (NCT03978520) are ongoing. However, the drug has also potential in CLL and other lymphoid malignancies.

\subsubsection{Tolebrutinib}

Tolebrutinib (SAR 442168, PRN 2246, Sanofi Genzyme) is an investigational BTKi with potential immunomodulatory, anti-inflammatory and anti-cancer activities in B-cell malignancies [73]. Tolebrutinib is able to cross the blood-brain barrier and inhibits the activity of BTK both peripherally and in the central nervous system (CNS). The phase $2 b$ trial evaluating the efficacy and safety of tolebrutinib showed significant reduction of disease activity associated with multiple sclerosis (NCT03996291) [74]. In addition, a multicenter, randomized, double blind, placebo-controlled, phase 3 study to evaluate the efficacy and safety of tolebrutinib in patients with myasthenia gravis has been initiated (ClinicalTrials.gov Identifier: NCT05132569).

\section{Reversible BTK inhibitors}

Reversible BTK inhibitors (BTK-i), such as pirtobrutinib and vecabrutinib, bind BTK non-covalently and do not require $\mathrm{C} 481$ to be present [75], thus overcoming this resistance mechanism. They can therefore inhibit BTK in the presence of the C481S mutation, and non-selective reversible BTK-i, including MK1026, may also overcome mutations within PLCG2 [76]. Results from ongoing studies of alternative BTK inhibitors will help define their role in CLL therapy as single drugs or in combination.

\subsection{Pirtobrutinib}

Pirtobrutinib (LOXO-305) is a highly selective, next generation BTKI which blocks the ATP binding site of BTK by noncovalent, non-C481-dependent binding, thus overcoming acquired resistance to covalent BTKis [77]. Recently, the results of the BRUIN phase $1 / 2$ study of pirtobrutinib performed in mature B-cell lymphoid malignancies has been reported, with promising results [78]. The study enrolled 323 patients, including 170 with heavily-pretreated R/R CLL. Among them, 25\% of patients had 17p deletion, 30\% TP53 mutation, 19\% 11q deletion, and 88\% unmutated IGHV. The median number of previous lines of therapy was 3 (range $2-5$ ). Moreover, $86 \%$ of patients had previously 
been treated with a BTKi, and 34\% with venetoclax. In the total population of CLL patients, ORR was 63\% including 79\% in del(17p) and/or TP53 mutated patients. In patients previously treated with other BTK inhibitors, ORR was $62 \%$. Moreover, ORR was similar in patients who previously discontinued another BTKi for progression $(67 \%)$ or toxicity (52\%). Importantly, in patients with a BTK C481 mutation, ORR was $75 \%$. The reported most common adverse events included fatigue (20\%), diarrhea (17\%), contusion (13\%), and grade 3 or higher neutropenia (10\%). Importantly, grade 3 atrial fibrillation/flutter were not observed, and only one patient with major bleeding was reported, caused by mechanical trauma. Only $1 \%$ discontinued treatment due to adverse events. A phase 3 global, randomized, open-label study comparing pirtobrutinib to investigator's choice of either idelalisib + rituximab or bendamustine + rituximab in CLL/SLL patients who have been treated with at least a covalent BTK inhibitor is ongoing (BRUIN CLL-321, ClinicalTrials.gov Identifier: NCT04666038)

\subsection{Vecabrutinib}

Vecabrutinib (SNS-062) is a selective, reversible, non-covalent, nanomolar potency and mutant BTKi [79]. In vitro studies have found it to demonstrate antitumor activity, even in cells that carry BTK Cys481Ser mutation. This dual activity is believed to result from vecabrutinib binding to the C481-independent BTK domain and suggests that it may have therapeutic potential in both covalent BTK relapse inhibitor disease and treatment-naive patients. Due to its very promising preclinical profile, this drug is being evaluated in $1 b / 2$ phase study in patients with various $B$ cell malignancies including CLL (NCT03037645) to potentially overcome ibrutinib resistance [80].

\subsection{Fenebrutinib}

Fenebrutinib (GDC-0853) is another selective, reversible, non-covalent inhibitor of BTK that does not require interaction with the Cys481 residue for its activity [81]. Structural analysis have identified unique fenebrutinib-BTK interactions, which may explain its selectivity. The in vitro activity of the compound was also preserved towards BTK demonstrating single and double lesions of C481S, T474A and T474S / C481S, respectively [82].

Fenebrutinib is currently undergoing clinical development, mainly for autoimmune disorders such as rheumatoid arthritis and systemic lupus erythematosus [83]. In addition, the drug was evaluated in $24 \mathrm{R} / \mathrm{R}$ patients with $24 \mathrm{~B}$-cell malignancies, including 14 with CLL (6 previously treated with BTK and positive for the C481S mutation) [84]. The ORR was approximately $30 \%$ with only one patient achieving CR. The most common AE of grade 3 or higher was anemia, which occurred in $12.5 \%$ of patients. Other AEs were fatigue $(38 \%)$, nausea $(33 \%)$, diarrhea $(29 \%)$, thrombocytopenia $(25 \%)$ and headache (21\%). Of the 14 patients with CLL, seven achieved an objective response, with a mean duration of 2.5 months. Three patients died from H1N1 infection, pneumonia, or disease progression.

\subsection{Rilzabrutinib}

Rilzabrutinib (PRN1008, Sanofi) is an is an oral, reversible, covalent BTKi designed for immune-mediated diseases [85]. The compound includes a functional nitrile group that acts as an electrophile that forms a covalent bond with the cysteine thiol. The reactivity of this complex makes it possible to reverse the reaction in vitro and in cellular conditions. Preclinical studies have shown rilzabrutinib to display anti-inflammatory effects in animal models of immune diseases. Rilzabrutinib alone, or with low doses of corticosteroids, was found to be effective and safe in pemphigus vulgaris [86]. It is also being investigated in a phase 3 trial for the treatment of immune thrombocytopenia, and in a phase 2 study for the autoimmune IgG4-related disease. In addition, phase 2 studies 
in asthma, atopic dermatitis, chronic spontaneous urticaria and warm autoimmune hemolytic anemia are planned.

\section{5. $M K 1026$}

MK1026 (ARQ 531) is a potent, reversible inhibitor of both wild type and ibrutinib-resistant C481S-mutant BTK. It also has a distinct kinase selectivity profile with strong inhibitory activity against several key oncogenic drivers from the TEC, Trk and Src family kinases. MK1026 demonstrated increased survival over ibrutinib in a murine

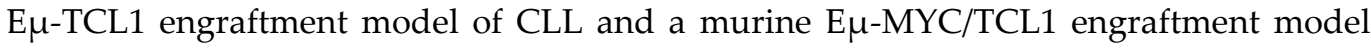
resembling Richter transformation [87].

Importantly, the drug also inhibits CLL cell survival and BCR-mediated activation of C481S BTK and PLC $\gamma 2$ mutants, which facilitate clinical resistance to ibrutinib. MK1026 was more effective than ibrutinib in prolonging survival in animal models and demonstrated in vitro activity in CLL cells harboring BTKC481S or PLC $\gamma 2$ resistance mutations [88]. The preliminary report from a phase I escalation trial found MK1026 to demonstrate clinical activity in patients with relapsed or refractory B-cell lymphoid malignancies [88]. Fourteen out of the 47 patients treated with MK1026 had PRs and additional 10 patients had stable disease. Responses were observed in patients with CLL , Richter's transformation, diffuse large B-cell lymphoma (DLBCL), and follicular lymphoma (FL).

\section{Resistance to BTK inhibitors}

Acquired resistance to covalent inhibitors is observed in approximately $60 \%$ of long-term treated patients with CLL $[88,89]$. In most cases, BTK resistance is caused by the development of clones with mutated cysteine (C481) in the ibrutinib binding site [90-92]. Among CLL/SLL patients who progressed after ibrutinib administration, mutations were found in the BTK Cys481, SH2 (BTK Thr316) and BTK Thr474 binding domains of BTK. Cysteine-to-serine mutations at the C481 site allow further signaling, including activation of PLC $\gamma 2$ and CARD11, thus bypassing inactive BTK and promoting the activation of distal BCR signaling. These changes result in cancer cell proliferation and migration.

In CLL, the mechanism of acalabrutinib resistance is similar to that of ibrutinib, and is related to BTK mutation [93]. In a study of 103 patients with CLL treated with acalabrutinib and routinely screened for BTK mutation, 22 were found to develop mutations. The median time from acalabrutinib initiation to mutation detection was 31.6 months. Among 16 patients with CLL progression, 11 (69\%) demonstrated BTK C481 mutations, including C481S in 10 patients, C481R in one and C481Y in another. Four patients demonstrated additional mutations to BTK C481S, including BTK T474I in one, BTK C481R in another and PLCG2 in two others. All these mutations had previously been identified in patients with ibrutinib resistance.

Several strategies for overcoming resistance to BTK have been investigated [94]. In particular, the third-generation, reversible, noncovalent BTK inhibitors display inhibitory activities against both BTK and BTKC481 mutants, and have the potential to overcome resistance to covalent inhibitors caused by BTKC481 mutation [95]. Noncovalent binding BTK inhibitors such as pirtobrutinib, vecabrutinib and MK1026 continue to inhibit BTK in the presence of the C481S mutation and have been found to be effective against C481 mutants [96]. Vecabrutinib and pirtobrutinib are more specific and inhibit wild-type and C481S-mutated BTK. MK1026 inhibits additional targets and has demonstrated activity in the presence of mutated PLCG2 [97]. Sequencing and combination therapies can also overcome BTKi resistance. Venetoclax is an active drug in CLL patients relapsed after ibrutinib. [98]. PI3K inhibitors, such as idelalisib, duvelisib or umbralisib, have also demonstrated therapeutic activity in CLL patients, previously treated with BTK inhibitors, who developed progression on treatment [99]. CD3×CD19 bispecific antibod- 
ies can mediate effective killing of CLL cells regardless of IGVH and TP53 mutational status, and irrespective of sensitivity to ibrutinib. Recent studies have also found CD3 $\times$ CD19 bispecific antibodies to be effective in killing ibrutinib-resistant CLL cells [100]. Chimeric antigen receptor-modified T (CAR-T) cell therapy has been investigated in CLL patients refractory to ibrutinib and showed promising activity. In the TRANSCEND CLL 004 phase 1/2 study, performed in R/R CLL patients failing on previous ibrutinib therapy, received CD19-directed CAR-T therapy; one half of the patients had previously failed on both ibrutinib and venetoclax [101, 102]. In addition, another new strategy for overcoming BTKi resistance is proteolysis-targeting chimera (PROTAC) induced degradation of BTK. PROTAC has been found to be effective in a mouse model of the BTK C481S mutation [103].

\section{Adverse events}

BTK inhibitors have unique toxicities that require monitoring. As such, it is essential to provide optimal management to achieve the best possible outcomes for patients [104, 105]. The most common reason for discontinuing ibrutinib is toxicity, particularly the AEs specific for this group of drugs, such as atrial fibrillation, bleeding events, arthralgias, rash, diarrhea, and cytopenias [106]. Ibrutinib discontinuation caused by AEs mainly AF, arthralgias, rash, diarrhea, and bleeding events, is observed in $4 \%-26 \%$. Acalabrutinib and zanubrutinib are selective next-generation covalent BTK inhibitors, with less off-target activity than ibrutinib and better tolerability. The most common AE associated with acalabrutinib with acalabrutinib is headache, observed in $22 \%-51 \%$ of patients. The incidence of atrial fibrillation is lower than for ibtrutinib. In patients treated with zanubrutinib, the most common grade $\geq 3$ AEs were neutropenia and infections. The following section summarizes the key BTK inhibitor-related AEs in patients with CLL, and strategies for their management.

\subsection{Bleeding and bruising}

Bleeding and bruising are frequently observed AEs in patients treated with BTKis [107]. In a systematic review and pooled analysis of four randomized controlled trials, ibrutinib treatment was associated with an increase in all-grade bleeding (4.85\% vs. $1.55 \%, \mathrm{RR}=2.93, \mathrm{P}=0.03$ ) compared to control treatments. This is believed to be partly due to the off-target Tec kinase inhibition and platelet inhibitory mechanisms [108, 109]. Acalabrutinib did not induce the platelet dysfunction or inhibition of platelet aggregation observed with ibrutinib [110]. However, bleeding complications were also observed in patients treated with acalabrutinib. In a pooled safety analysis of zanubrutinib monotherapy in patients with B-cell malignancies, bruising occurred in $25 \%$ of patients and major hemorrhage in $4 \%$ [111]. The risk of bleeding and bruising is more common in patients simultaneously treated with antiplatelet drugs and anticoagulants; in these patients, serious life-threatening bleedings were observed. The ibrutinib-associated risk of bleeding can decrease by prohibiting the use of oral anticoagulants and by avoiding CYP3A4 drug-drug interactions [112]. It is therefore recommended to stop BTKi treatment for three days before and after any minor invasive procedure, and for seven days before and after a major surgical procedure, to decrease the risk of bleeding. Patients considered to receive BTKis should be advised to stop aspirin treatment or reduce the dose to $81 \mathrm{mg}$ if necessary. However, patients with episodes of bleeding or bruising should not receive anticoagulation treatment if possible. Achieving optimal anticoagulation therapy in patients with atrial fibrillation during BTKi treatment is a difficult challenge. For patients with new atrial fibrillation, anticoagulation should be recommended to decrease the risk of stroke. Apixaban is usually suggested following an analysis of the risks and benefits. However, the need for BTKi continuation should be considered. 


\subsection{Cardiovascular complications}

Cardiotoxicity is an important complication of treatment with ibrutinib and other BTKis. A pooled analysis of four randomized controlled clinical trials found ibrutinib to be associated with an increased risk of $\mathrm{AF}$ and flutter compared to other treatments (3.03\% vs. $0.80 \%, R R=3.80, p=0.003$ [113]. In another study of 178 patients with CLL, those who discontinued ibrutinib-based therapy gave atrial fibrillation as the most common reason for discontinuation [114]. Long-term data indicates that approximately $20 \%$ of ibrutinib-treated patients develop incidences of arrhythmia $[115,116]$.

A review of the Food and Drug Administration Adverse Event Reporting System (FAERS) database by Grewel et al examined the cardiovascular complications associated with novel agents in CLL, including ibrutinib and acalabrutinib [117]. A total of 6074 cardiac adverse events were identified. Of the examined agents, ibrutinib was found to have the highest risk of cardiac adverse events $(4832 / 36581 ; 13.2 \%)$. The ibrutinib group also demonstrated a higher frequency of $\mathrm{AF}(41.5 \%)$ than in the group treated with acalabrutinib (age-adjusted $\mathrm{OR}=2.21,95 \% \mathrm{CI}=1.25-3.90, \mathrm{p}=0.005$ ). However, hypertension was higher in the acalabrutinib group (25.6\%). This observation supports the hypothesis that AF can be provoked by the effect of ibrutinib on an off-target site. A recent study suggests that AF caused by ibrutinib is related to inhibition of C-terminal Src kinase; however, similar mortality due to cardiac events was observed in the ibrutinib $(16.2 \%)$ and acalabrutinib (15.2\%) groups. A pooled safety analysis of zanubrutinib monotherapy in a group of 779 patients with B-cell malignancies found AF to occur in $3 \%$; for such patients, multidisciplinary care is indicated to optimize anticoagulant treatment and cardiac management. Ibrutinib is associated with a significantly-increased risk of hypertension [118]. In an early-phase study of ibrutinib in CLL, $23 \%$ of patients developed new or worsened existed hypertension and follow-up data suggests a continual increase in the incidence of hypertension over time [119, 120]. In a recent analysis by Dickerson et al., $78.3 \%$ of patients treated with ibrutinib developed new or worsened hypertension over a median observation period of 30 months [121]. Hypertension developed in $71.6 \%$ of patients, with a time to $50 \%$ cumulative incidence of 4.2 months. In addition, $17.7 \%$ of the patients developed high-grade hypertension with blood pressure above $160 / 100 \mathrm{~mm} \mathrm{Hg}$. In multivariate regression, new or worsened hypertension was associated with increased major adverse cardiovascular events (MACEs) (hazard ratio [HR], 2.17; 95\% confidence interval [CI], 1.08-4.38). No single antihypertensive class was associated with the prevention or control of ibrutinib-related hypertension. However, antihypertensive initiation was associated with a lower risk of MACE (HR, 0.40; 95\% CI, 0.24-0.66). Collectively, these data suggest that ibrutinib is associated with a substantial increase in the incidence and severity of hypertension, and an increased risk of cardiotoxic events. Studies have found a lower burden of hypertension among patients receiving acalabrutinib than those receiving ibrutinib. Grade $\geq 3$ hypertension was also observed in $5 \%$ of patients with lymphoid malignancies treated with zanubrutinib [111].

\subsection{Cytopenias}

Cytopenias are relatively frequent AEs in patients treated with BTKi but they are usually not serious, and are typically managed with supportive care and/or treatment interruption. Severe cytopenias are rarer in CLL patients treated with BTK inhibitors than other antileukemic drugs and usually do not warrant dose reduction. Among patients treated with zanubrutinib, grade $\geq 3$ neutropenia was observed in $23 \%$, thrombocytopenia in $8 \%$, and anemia in $8 \%$ [111]. BTK inhibitor treatment should be withheld from patients demonstrating grade $\geq 3$ neutropenia and infection or fever until resolution to baseline or grade 1; following this, the treatment can be restarted at a reduced dose. In addition, patients demonstrating grade 3 thrombocytopenia with bleeding or grade 4 thrombocytopenia, should not receive BTK inhibitor treatment until resolution to baseline or grade 1 , following which BTKi treatment can be restarted at a reduced dose. If cytopenia occurs 
for a fourth time, the BTKis should be discontinued. Treatment-emergent autoimmune cytopenias were observed in $1 \%$ of patients during ibrutinib therapy [122]. In a phase 2 study evaluating acalabrutinib monotherapy in $134 \mathrm{R} / \mathrm{R}$ CLL patients, only one case of AIHA recurrence was noted among 11 patients with a history of autoimmune cytopenia. In addition, ibrutinib induces rapid and durable responses when used to treat autoimmune hemolytic anemia (AIHA) developed in CLL patients [123].

\subsection{Infections}

BTK plays an important role in immunity, participating in numerous pathways including B cells, T cells and macrophages. It is therefore a driving factor in both lymphoproliferative disorders and response to infection [124]. BTK inhibitors are considered less immunosuppressive and safer than other chemotherapeutic drugs and have been proposed as useful agents for reconstituting humoral immunity and protecting against infection in patients with CLL [125]. In addition, ibrutinib can inhibit inflammation induced by bacterial infection. This agent diminishes myeloid cell activation and migration during lung inflammation and can resolve acute lung inflammation during pneumococcal pneumonia [126].

In addition, BTK expressed in neutrophils regulated inflammation in the respiratory region during acute lung injury in mice. Inhibition of BTK activity increased survival and reduced the morphological changes associated with Influenza A virus infection, confirming its protective influence in the lung during influenza-induced inflammation [127]. However, several clinical trials indicate an increased risk of infection, including upper respiratory tract infection, pneumonia, cellulitis and sepsis [120]. In a recent retrospective, single-center study of patients treated with ibrutinib, $11.4 \%$ of the patients developed serious infections requiring hospitalization or parenteral therapy, including $4.2 \%$ with invasive fungal infections [128]. In another study, the incidence of one or more serious infections in patients with hematologic malignancies receiving ibrutinib therapy was $18.0 \%$; most (16.1\%) were bacterial in nature and $4.3 \%$ multiple infections [129]. In a pooled analysis from 1476 ibrutinib-exposed patients, the incidence of Grade $\geq 3$ infection was $21 \%$. Grade $\geq 3$ infection was observed in $27 \%$ patients receiving zanubrutinib. This value is similar to that reported in a pooled analysis from ibrutinib-exposed patients.

At present, the individual contribution of BTKis to the risk of serious infection is unclear. A body of evidence indicates that this risk is influenced by various additional factors such as concurrent steroid use, neutropenia, and prior chemo- or immunochemotherapy [128, 129]. In patients with multiple risk factors, targeted antimicrobial prophylaxis may reduce the risk of infection associated with BTKi use. Vaccination is also indicated (e.g., against influenza, COVID-19 and pneumococcus) are recommended before treatment initiation $[130,131]$. Recombinant, adjuvanted varicella-zoster virus vaccine should be also considered [132]. Iintravenous immunoglobulin supplementation is also useful for patients with recurrent infections and hypogammaglobulinemia.

\subsection{Arthralgias and myalgias}

The occurrence of arthralgias/myalgias is common AE in CLL patients treated with ibrutinib in both upfront and relapsed/refractory $(R / R)$ settings, with an increased risk observed at longer treatment durations [133-138]. In clinical trials and retrospective studies, arthralgias and myalgias were noted in $11-36 \%$ of patients [135-138]. In a recent analysis, 76 of 214 (36\%) patients with CLL treated with ibrutinib, either as a single agent or in combination, patients developed arthralgias/myalgias during follow-up with a median follow-up of 34.5 months [133]. Most patients (79\%) had grade 1 or 2 toxicity and $28 \%$ continued ibrutinib with resolution of symptoms. More effective toxicity management was observed for dose holds of ibrutinib than dose reduction. However, 63\% of patients with grade 3 or higher toxicity discontinued ibrutinib treatment, indicating that this subgroup does not tolerate ibrutinib. For some patients, the use of non-steroidal an- 
ti-inflammatory drugs, acetaminophen, or corticosteroids can temporary reduce symptoms; however, these drugs may exacerbate the risk of bleeding and should be used with caution [137]. The mechanisms behind of ibrutinib-induced arthralgias/myalgias remain unclear.

Additional studies are needed to determine the mechanism of ibrutinib-related arthralgias/myalgias and develop optimal management strategies. Rhodes et al recommend continuing ibrutinib at the current dose in the case of grade 1 or 2 arthralgias/myalgias, as long as the symptoms do not interfere with activities of daily living, as most patients can resolve spontaneously [133]. If symptoms affect daily activities, dose reduction should be advised. If there is no improvement at a lower dose, further dose reduction or a dose hold until improvement in symptoms should be recommended. Permanent discontinuation of ibrutinib and use of alternative CLL directed therapies is indicated if symptoms recur with re-challenge after a dose hold. For patients with grade 3 or higher arthralgias/myalgias, dose hold until resolution of symptoms is indicated. If symptoms resolve, re-challenging with a lower dose of ibrutinib should be used. If symptoms do not recur, continuing the reduced dose of ibrutinib seems to be better strategy than attempting to escalate. If symptoms recur, ibrutinib should be discontinued other CLL-directed therapies and considered BTKi. Replacing ibrutinib with acalabrutinib is a reasonable option, as acalabrutinib seems not cause myalgias. A recent study indicates that approximately two-thirds of patients with ibrutinib-induced arthralgias/myalgias did not experience recurrent symptoms following acalabrutinib treatment [138].

\subsection{Dermatologic complications}

Approximately $20 \%$ of patients treated with ibrutinib or acalabrutinib demonstrate rashes, which have been associated with EGFR inhibition and infiltration of inflammatory cells $[139,140]$. Witholding the BTKi is usually recommended and if the rash resolves, the BTK inhibitor can be resumed. However, if the rash recurs, a dose reduction is indicated. In addition, erythema nodosum was observed in patients treated with ibrutinib. Both skin symptoms usually respond to corticosteroids or dose holds. Textural changes in hair and nails are also observed. A higher incidence of brittle fingernails or toenails, with the formation of vertical nail ridges, were also observed during long-term therapy with ibrutinib [141]. These manifestations appear gradually, with a median reported onset of nine months, and do not represent a dose-limiting toxicity. They can be treated with biotin supplementation and the application of nail oil.

\subsection{Headaches}

Headaches are noted approximately in $40 \%$ of patients treated with acalabrutinib, and are rarely observed in patients receiving ibrutinib [142]. Usually, headaches occur early after treatment initiation and the incidence decreases over time. This AE is usually a manageable toxicity and does not influence the continuation of BTKi treatment.

\subsection{Diarrhea}

Diarrhea is commonly observed AE in patients treated with BTKi. It is observed mainly in the first six months from beginning therapy, with a frequently observed self-limited course [131]. Similar incidence is observed between patients treated with ibrutinib and acalabrutinib [143]. Temporary drug holds should be considered in the case of grade $\geq 3$ diarrhea [131].

\section{BTK inhibitors and the COVID-19 pandemic}


As BTK regulates the activity of macrophages, it has been suggested that BTK inhibitors may have a therapeutic role in COVID-19 patients. This hypothesis was supported by the observation that activated macrophages were responsible for the hyperinflammatory immune response observed in patients with severe COVID-19 symptoms $[144,145]$. In patients with severe COVID-19, treatment with acalabrutinib was associated with rapid clinical improvement, with increased oxygenation and reduced inflammation being observed in the majority of patients. However, it is important to note that BTK inhibitors impair the innate immunity and increase susceptibility to infections. Despite this, long-term BTKi therapy may improve recovery of humoral immune function, decrease infection rates and protect CLL patients from lung injury in the event of COVID-19 infection [146]. The use of BTKi therapy is supported by a pilot study in six CLL patients with COVID-19 infection who continued therapy [147].

\section{Conclusions}

BTK inhibitors are promising new drugs which demonstrate high efficacy in previously untreated and R/R CLL. Second generation irreversible BTKis, including acalabrutinib and zanubrutinib, show greater selectivity than ibrutinib, with minimal off-target activity and better safety profiles. New reversible BTKi as fenebrutinib, pirtobrutinib and MK1026, pirtobrutinib, vecabrutinib and MK1026 inhibit BTK in the presence of the C481S mutation and are effective in patients resistant to irreversible BTK inhibitors. The development of novel, more specific and less toxic BTKi is important not only for the treatment of CLL but also for a significant number of neoplastic and immune-mediated diseases with yet unmet treatment needs. When used as a single drugs, BTK inhibitors are given continuously until disease progression or unacceptable toxicity. Several ongoing studies are focusing on time-limited combination therapy strategies such as combinations with venetoclax and anti-CD20 monoclonal antibodies. Moreover, combination therapy may elicit a deeper response and use for a limited time. However, the toxicity, costs and efficacy of the drug should be should be taken into account when deciding on the optimal therapeutic solution. This section is not mandatory but may be added if there are patents resulting from the work reported in this manuscript.

Author Contributions: P.S., M.W. and T.R. contributed equally to the concept tion/design, writing, and approval of the final version of the paper.

Funding: This work was supported by the grants from the Medical University of Lodz, Poland (No. 503/1-093-01/503-11-004 and 503/1093-1/503-11-003).

Conflicts of Interest: P.S. received research founding by ROCHE and Takeda; M.W. received research funding by ROCHE and Takeda; T.R. served as a consultant for Janssen, Abbvie, BeiGene, AstaZeneca and Octapharma and received honoraria and research funding from Janssen, Abbvie, BeiGene, AstaZeneca, Octapharma, GSK, Karyopharm, Sanofi, Takeda and Regeneron, outside the submitted work.

\section{References}

1. Hallek, M.; Cheson, B.D.; Catovsky, D.; Caligaris-Cappio, F.; Dighiero, G.; Dohner, H.; Hillmen, P.; Keating, M.; Montserrat, E.; Chiorazzi, N.; et al. iwCLL guidelines for diagnosis, indications for treatment, response assessment, and supportive management of CLL. Blood. 2018, 131, 2745-2760

2. Eichhorst, B.; Robak, T.; Montserrat, E.; Ghia, P.; Niemann, C.U.; Kater, A.P.; Gregor, M.; Cymbalista, F.; Buske, C.; Hillmen P.; Hallek, M.; Mey, U. ESMO Guidelines Committee. Chronic lymphocytic leukaemia: ESMO Clinical Practice Guidelines for diagnosis, treatment and follow-up. Ann. Oncol. 2021, 32, 23-33.

3. Howlader, N.; Noone, A.M.; Krapcho, M.; Miller, D.; Brest, A.; Yu, M.; Ruhl, J.; Tatalovich, Z.; Mariotto, A.; Lewis, D.R.; et al. (Eds.)SEER Cancer Statistics Review, 1975-2016; National Cancer Institute: Bethesda, MD, USA, 2019; 
Based on November 2018SEER Data Submission, Posted to the SEER Web Site. Available online: https://seer.cancer.gov/csr/1975_2016/ retrieved on April 302019.

4. Alrawashdh, N, Sweasy, J.: , Erstad, B.: McBride, A.: Persky, D.O.: Abraham, I. Survival trends in chronic lymphocytic leukemia across treatment eras: US SEER database analysis (1985-2017). Ann. Hematol. 2021, 100, 2501-2512.

5. Brullo, C,; Villa, C,; Tasso, B,: Russo, E,: Spallarossa, A. Btk Inhibitors: A Medicinal Chemistry and Drug Delivery Perspective. Int J Mol Sci. 2021, 22, 7641.

6. Wen, T, Wang, J, Shi, Y,: Quian, H.; Li, P. Inhibitors targeting Bruton's tyrosine kinase in cancers: drug development advances. Leukemia 2021, 35, 312-332,;

7. Robak, T,; Robak P. BCR signaling in chronic lymphocytic leukemia and related inhibitors currently in clinical studies. Int Rev Immunol. 2013,32:358-376.

8. Burger, J.A.; Chiorazzi N. B cell receptor signaling in chronic lymphocytic leukemia. Trends Immunol. 2013, 34, 592-601.

9. Burger, J.A,.: Tedeschi A, Barr,P.M.; Robak, T,; Owen, C,; Ghia, P,; Bairey, O,; Hillmen, P,; Bartlett, N.L. et al: Ibrutinib as initial therapy for patients with chronic lymphocytic leukemia. N .Engl. J. Med. 2015, 373, $2425-2437$.

10. Byrd, J.C.; Brown, J.R.; O’Brien, S.; Barrientos, J.C.; Kay, N.E.; Reddy, N.M.; Coutre, D.; Tam, C.S.; et al. Ibrutinib versus ofatumumab in previously treated chronic lymphoid leukemia. N Engl J Med. 2014, 371, $213-223$.

11. Ghia, P.; Pluta, A.; Wach, M.; Lysak, D.; Kozak, T.; Simkovic, M.; Kaplan, P.; Kraychok, I.; Illes, A.; de la Serna, J.; et al. Acalabrutinib vs rituximab plus idelalisib (IdR) or bendamustine (BR) by investigator choice in relapsed/refractory (RR) chronic lymphocytic leukemia: phase 3 ASCEND study. Hematol. Oncol. $2019,37,86-87$.

12. Sharman. J.P.; Egyed,; M, Jurczak,; W,; Skarbnik,; A, Pagel,; J.M,; Flinn, I.W,; Kamdar, M,; Munir T,; Walewska R, et al. Acalabrutinib with or without obinutuzumab versus chlorambucil and obinutuzmab for treatment-naive chronic lymphocytic leukaemia (ELEVATE TN): a randomised, controlled, phase 3 trial. Lancet. 2020, 395, 1278-1291.

13. Zain, R.; Vihinen, M. Structure-function relationships of covalent and non-Covalent BTK inhibitors. Front Immunol. 2021, 12, 694853.

14. Estupiñán, H,Y,; Wang, Q; Berglöf, A,; Schaafsma, G.C.P, ; Shi, Y,; Zhou. L,; Mohammad, D.K,; Yu L, Vihinen, M,; Zain, R,; Smith, C.I.E. BTK gatekeeper residue variation combined with cysteine 481 substitution causes super-resistance to irreversible inhibitors acalabrutinib, ibrutinib and zanubrutinib. Leukemia 2021, 35, 1317-1329.

15. Byrd, J.; Furman, R.R,; Coutre, S.E.; Flinn, I.W,; Burger, J.A,; Blum, K.A,; Grant, B,; Sharman, J.P, Coleman M, Wierda WG, et al. Single-agent ibrutinib in treatment-naive and relapsed/ refractory chronic lymphocytic leukemia: a 5-year experience. Blood 2018; 131: 1910-1919.

16. Byrd, J.; Hillmen, P,; Ghia, P,; Kater, A.P,; Chanan-Khan, A,; Furman, R.R, O'Brien, S,; Yenerel, M.N,; Illés, A,; Kay, $\mathrm{N}$; et al. Acalabrutinib versus Ibrutinib in previously treated chronic lymphocytic leukemia: results of the first randomized phase III trial. J. Clin. Oncol. 2021, 39, 3441-3452.

17. Hillmen. P,; Eichhorst. B,; Brown, J.R,; Lamanna, N,; O'Brien, S,; Tam, C.S,; Qiu, L,; Kazmierczak, M,; Zhou, K,; Šimkovič, M,; Mayer, J, et al. First interim analysis of alpine study: results of a phase 3 randomized study of zanubrutinib vs ibrutinib in patients with relapsed/refractory chronic lymphocytic leukemia/small lymphocytic lymphoma. EHA Library. 06/11/21; 330170; LB1900.https://ibrary.ehaweb.org/eha/2021/eha2021-virtual congress/330170/peter.hillmen.first.interim.analysis.of.alpine.study.results.of.a.phase.3.html?f=listing\%3D0\%2Abrow seby\%3D8\%2Asortby\%3D1\%2Asearch\%3Dlb1900.

18. Ahn, I.E;; Brown, J.R. Targeting Bruton's tyrosine kinase in CLL. Front. Immunol. 2021, 12, 687458.

19. Woyach , J,A,; Bojnik, E.; Ruppert, A,S,: Stefanovski, Matthew.R.; Goettl, V.M.; Smucker, Byrd, J.; L.S.J.; Dubovsky, Towns, W,H,: MacMurray, M.M.,: et al. Bruton's tyrosine kinase (BTK) function is important to the development and expansion of chronic lymphocytic leukemia (CLL). Blood 2014, 123, 1207-1213.

20. Gauld, S.B., Dal Porto, J.M., Cambier, J.C. B Cell antigen receptor signaling: roles in cell development and disease. Science 2002, 296, 1641-1642.

21. Davis, R,E; Ngo, V.N,; Lenz, G,; Tolar, P,; Young, R.M, ; Romesser P.B,; Kohlhammer, H,; Lamy, L,; Zhao, H, Yang, Y, et al.: Chronic Active B-Cell-Receptor Signalling in Diffuse Large B-Cell Lymphoma. Nature 2010, 463, 88-92.

22. Kaptein, A.; de Bruin, G.; Emmelot-van Hoek, M.; van de Kar, B.; de Jong, A.; Gulrajani, M.; Demont, D.; Covey, T.; Mittag, D.; Barf, T. Potency and selectivity of BTK inhibitors in clinical development for B-Cell malignancies. Blood. 2018,132, 1871. 
23. Alsadhan, A.; Cheung, J.; Gulrajani, M.; Gaglione, E.M.; Nierman, P.; Hamdy, A.; Izumi, R.; Bibikova, E.; Patel, P.; Sun, C.; et al. Pharmacodynamic analysis of BTK inhibition in patients with chronic lymphocytic leukemia treated with acalabrutinib. Clin Cancer Res. 2020 ,26, 2800-2809.

24. Lynch, T.J.; Kim, E.S.; Eaby, B.; Garey, J.; West, D.P.; Lacouture, ME. Epidermal growth factor receptor inhibitor-associated cutaneous toxicities: an evolving paradigm in clinical management. Oncologist. 2007, 12, 610-621.

25. Barf, T.; Covey, T.; Izumi, R.; van de Kar, B.; Gulrajani, M.; van Lith, B.; van Hoek, M.; de Zwart, E.; Mittag, D.; Demont, D.; et al. Acalabrutinib (ACP-196): a covalent bruton tyrosine kinase inhibitor with a differentiated selectivity and in vivo potency profile. J Pharmacol Exp Ther. 2017, 363, 240-252.

26. Pan, Z.; Scheerens, H.; Li, S.J.; Schultz, B.E.; Sprengeler, P.A.; Burrill, L.C.; Mendonca, R.V.; Sweeney, M.D.; Scott, C.K.; Grothaus, P.G.; et al. Discovery of selective irreversible inhibitors for Bruton's tyrosine kinase. Chem Med Chem. 2007, 2, 58-61.

27. Honigberg, L.A.; Smith, A.M.; Sirisawad, M.; Verner, E.; Loury, D.; Chang, B.,; Li, S.; Pan, Z.; Thamm, D.H.; Milleret, R.A.; al. The Bruton tyrosine kinase inhibitor PCI-32765 Blocks B-Cell activation and is efficacious in models of autoimmune disease and B-Cell malignancy. Proc Natl Acad Sci USA. 2010, 07, 13075-1380.

28. Brown, J.R. How i treat CLL patients with ibrutinib. Blood 2018,131:379-386.

29. Heerema, N.A,. Luan, Y, Liu, E.A,; Dean, J.P,; O'Brien, S. Ibrutinib treatment for first-line and relapsed/refractory chronic lymphocytic leukemia: final analysis of the pivotal phase Ib/II PCYC-1102 study. Clin. Cancer Res. 2020, 26, 3918-3927.

30. Byrd, J.C.; Hillmen, P.; O Brien, S.; Barrientos, J.C.; Reddy, N.M.; Coutre, S.; Tam C.S.; Mulligan, S.P.; Jaeger, U.; Barr, P.M.; et al. Long-term follow-up of the RESONATE phase 3 trial of ibrutinib vs ofatumumab. Blood. 2019, 133, 2031-2042.

31. Munir, T.; Brown, J.R.; O’Brien, S.; Barrientos, J.C.; Barr, P.M.; Reddy, N.M.; Coutre, S.; Tam, C.S.; Mulligan, S.P.; Jaeger, U.; et al. Final analysis from RESONATE: up to six years of follow-up on ibrutinib in patients with previously-treated chronic lymphocytic leukemia or small lymphocytic lymphoma. Am J Hematol. 2019, 94, $1353-1363$.

32. Hillmen, P.; Rawstron, A.C.; Brock, K.; Munoz-Vicente, S.; Yates, F.J.; Bishop, R.; Boucher, R.; MacDonald, D.; Fegan, C.; McCaig, A.; et al. Ibrutinib plus venetoclax in relapsed/refractory chronic lymphocytic leukemia: the CLARITY study. J Clin Oncol. 2019, 37, 2722-2729.

33. Jaglowski, S.M.; Jones, J.A.; Nagar, V.; Flynn, J.M.; Andritsos, L.A.; Maddocks, K.J.; Woyach, J.A.; Blum, K.A.; Grever, M.R.; Smucker, K.; et al. Safety and activity of BTK inhibitor ibru- tinib combined with ofatumumab in chronic lymphocytic leu- kemia: a phase 1b/2 study. Blood. 2015, 126, 842-850.

34. Jain, P.; Keating, M.J.; Wierda, W.G.; Sivina, M.; Thompson, P.A.; Ferrajoli, A.,; Estrov, Z.; Kantarjian, H.; O'Brien, S.; Burger, J.A.; Long-term follow-up of treatment with ibrutinib and rituximab in patients with high-risk chronic lympho- cytic leukemia. Clin Cancer Res. 2017, 23, 2154-2158.

35. Burger, J.A.; Sivina, M.; Jain, N.; Kim, E.; Kadia, T.; Estrov, Z.; Nogueras-Gonzalez, G.M.; Huang, X.; Jorgensen, J.; Li, J.; et al. Randomized trial of ibrutinib vs ibrutinib plus rituximab in patients with chronic lymphocytic leukemia. Blood. 2019, 133, 1011-1019.

36. Fraser, G.; Cramer, P.; Demirkan, F.; Silva, R.S.; Grosicki, S.; Pristupa, A.; Janssens, A.; Mayer, J.; Bartlett, N.L.; Dilhuydy, M.S.; et al. Updated results from the phase 3 HELIOS study of ibrutinib, bendamustine, and rituximab in relapsed chronic lymphocytic leukemia/small lymphocytic lymphoma. Leukemia. 2019, 33, 969-980

37. Hillmen, P.; Fraser, G.; Jones, J.; Rule, S.; Brien, S.; Dilhuydy, M.S.; Pristupa, A.; Janssens, A.; Mayer, J.; Bartlett, N.L.; et al. Comparing single-agent ibrutinib, bendamustine plus rituximab (BR) and ibrutinib plus BR in patients with previously-treated chronic lymphocytic leukemia/small lymphocytic lymphoma (CLL/SLL): an indirect comparison of the RESONATE and HELIOS trials. Blood. 2015,129, 2944.

38. Burger, J.A.; Barr, P.M.; Robak, T.; Owen, C.; Ghia, P.; Tedeschi, A.; Bairey, O.; Hillmen, P.; Coutre, S.E.; Devereux, S.; et al. Long-term efficacy and safety of first-line ibrutinib treatment for patients with CLL/SLL: 5 years of follow-up from the phase 3 RESONATE-2 study. Leukemia. 2020, 34, 787-798

39. Moreno, C.; Greil, R.; Demirkan, F.; Tedeschi, A.; Anz, B.; Larratt, L.; Simkovic, M.; Samoilova, O.; Novak, J.; Ben-Yehuda, D.; et al. Ibrutinib plus obinutuzumab versus chlorambucil plus obinutuzumab in first-line treatment of chronic lymphocytic leukaemia (iLLUMINATE): a multicentre, randomised, open-label, phase 3 trial. Lancet Oncol. 2019, 20, 43-56.

40. Woyach, J.A.; Ruppert A.S.; Heerema, N.A.; Zhao, W.; Booth, A.M.; Ding, W.E.; Bartlett , N.L.; Brander, D.M.; Barr, P.M.; Rogers, K.A.; et al. Ibrutinib Regimens versus Chemoimmunotherapy in Older Patients with Untreated CLL. N Engl J Med. 2018, 379, 2517-2528.

41. Shanafelt, T.D.; Wang, W.; Xin, V.; Kay, N.E.; Hanson, C.A.; O'Brien, S.; Barrientos, J.; Jelinek, D.A.; et. al. Ibrutinib Rituximab or Chemoimmunotherapy for Chronic Lymphocytic Leukemia. N Engl J Med. 2019, 381, 432-443. 
42. Byrd, J.C.; Harrington, B.; O’Brien, S.; Jones, J.A.; Schuh, A.; Devereux, S.; Chaves, J.; Wierda, W.G.; Awan, F.T.; Brown, J.R.; et al. Acalabrutinib (ACP-196) in relapsed chronic lymphocytic leukemia. N Engl J Med. 2016, 374, 323-332.

43. Byrd, J.C.; Wierda, W.G.; Schuh, A.; Devereux, S.; Chaves, J.M.; Brown, J.R.; Hillmen, P.; Martin, P.; Awan, F.T.; Stephens, D.M.; et al. Acalabrutinib monotherapy in patients with relapsed/refractory chronic lymphocytic leukemia: updated phase 2 results. Blood. 2020, 135, 1204-1213.

44. Byrd, J.C,; Woyach, J.A,; Furman, R.R,; Martin, P,; O'Brien, S,; Brown JR, Stephens, D.M, .Barrientos, J.C,; Devereux S, Hillmen, $\mathrm{P}$, et al. Acalabrutinib in treatment-naive chronic lymphocytic leukemia. Blood 2021, 137, 3327-3338.

45. Woyach, J.A,; Blachly, J.S.; Rogers, K.A.; Bhat, S.A.; Jianfar, M.; Lozanski, G.; Weiss, D.M.; Andersen, B.L.; Gulrajani, M.; Frigault, M.M.; et al. Acalabrutinibplus obinutuzumab in treatment-naive and relapsed/refractory chronic lymphocytic leukemia. Cancer Discov. 2020, 10, 394-405.

46. Sharman, J.P,; Egyed, M,; Jurczak, W,; Skarbnik, A,; Pagel. J.M,; Flinn, I.W,; Kamdar, M,; Munir, T,; Walewska, R,; Corbett, G; et al. Acalabrutinib \pm obinutuzumab versus obinutuzumab + chlorambucil in treatment-naïve chronic lymphocytic leukemia: Elevate-TN four-year follow up. J. Clin. Oncol. 2021; 39 (Suppl), 7509-7509.

47. Ghia, P,; Pluta, A,; Wach, M, Lysak, D,; Kozak, T,; Simkovic,, M,; Kaplan, P,; Kraychok, I,; Illes, A,; de la Serna J, et al. ASCEND: Phase III, randomized trial of acalabrutinib versus idelalisib plus rituximab or bendamustine plus rituximab in relapsed or refractory chronic lymphocytic leukemia. J. Clin. Oncol. 2020, 38, $2849-2861$.

48. Byrd, J.C,; Hillmen, P,;Ghia, P,; Kater, A.P,; Chanan-Khan, A,; Furman, R.R,; O'Brien, S,; Yenerel, M.N,; Illés, A,; Kay, $N_{\text {; }}$; et al. Acalabrutinib versus ibrutinib in previously treated chronic lymphocytic leukemia: results of the first randomized phase III trial. J Clin Oncol. 2021,39,3441-3452.

49. Sheng, Z,; Song, S,; Yu, M,; Zhu, H,; Gao, A,; Gao, W,; Ran, X,;Huo, D. Comparison of acalabrutinib plus obinutuzumab, ibrutinib plus obinutuzumab and venetoclax plus obinutuzumab for untreated CLL: a network meta-analysis. Leuk Lymphoma 2020, 61, 3432-3439.

50. Robak, P,; Robak, T. Novel synthetic drugs currently in clinical development for chronic lymphocytic leukemia. Expert Opin. Investig. Drugs 2017, 26,1249-1265.

51. Tam, C,; Grigg, A.P,; Opat, S, Ku, M.; Gilbertson M ,; Anderson, M.A,: Seymur, J.F, Ritchie , D.S,: Dircoletto, C.; Dimowski, B.: et al. The BTK inhibitor, BGB-3111, is safe, tolerable, and highly active in patients with relapsed/refractory B-cell malignancies: initial report of a phase 1 first-in-human trial. Blood 2015, $126,832$.

52. Tam,C; Giannopoulos, K.; Jurczak, W, ; Šimkovič, M.; Shadman, M.; Österborg, A.; Laurenti, L.; Walker, P.; Opat,S.; Chan, H. et al. SEQUOIA: Results of a phase 3 randomized study of zanubrutinib versus bendamustine + Rituximab (BR) in patients with treatment-naïve (TN) chronic lymphocytic leukemia/small lymphocytic lymphoma (CLL/SLL). Blood 2021,138 (Suppl. 1), abstract 396)

53. Flinsenberg, T.W.H.; Tromedjo, C.C.; Hu, N.; Liu, Y.; Guo, Y.; Thia, K.Y.T.; Noori, T.; Song, X.; Yeang, H.X.A.; Tantalo, D.G. et al. Differential effects of BTK ;inhibitors ibrutinib and zanubrutinib on NK-cell effector function in patients with mantle cell lymphoma. Haematologica. 2020, 105, e76-79.

54. Zou, Y.X.; Zhu, H.Y.; Li, X.T.; Xia, Y.; Miao, K.R.; Zhao, S.S.; Wu, J-I.; Wang, L.; Xu, W.; Li, J-Y.; et al. The impacts of zanubrutinib on immune cells in patients with chronic lymphocytic leukemia/small lymphocytic lymphoma. Hematol Oncol. 2019, 37, 392-400.

55. Tam, C.S.; Trotman, J.; Opat, S.; Burger, J.A.; Cull, G.; Gottlieb, D.; Harrup, R.; Johnston, P.B.; Marlton, P.; Munoz, J.; et al. Phase 1 study of the selective BTK inhibitor zanubrutinib in B- cell malignancies and safety and efficacy evaluation in CLL. Blood. 2019, 134, 851-859

56. Cull, G,; Simpson, D, Opat, S, et al.: Treatment with the Bruton tyrosine kinase inhibitor zanubrutinib (BGB-3111) demonstrates high overall response rate and durable responses in patients with chronic lymphocytic leukemia/small lymphocytic lymphoma (CLL/SLL): Updated results from a phase 1/2 Trial. Blood $2019,134500$.

57. Tam, C.S,; Robak, T,; Ghia,; P, Kah,l B.S,; Walker, P,; Janowski,; W, Simpson, D,; Shadman, M,; Ganly, P.S,; Laurenti $\mathrm{L}$, et al. Zanubrutinib monotherapy for patients with treatment naïve chronic lymphocytic leukemia and $17 \mathrm{p}$ deletion. Haematologica. 2020, 106, 2354-2363.

58. Hillmen, P,; Brown J.R,; Eichhorst, B.F,; Lamanna, N,; O'Brien, SM,; Qiu, L,; Salmi, T, Hilger, J,; Wu, K,; Cohen, et al. ALPINE: zanubrutinib versus ibrutinib in relapsed/refractory chronic lymphocytic leukemia/small lymphocytic lymphoma. Future Oncol. 2020;16:517-523

59. Soumerai, J.D,; Mato, A.R,; Dogan, A,; Seshan, V.E,; Joffe, E,; Flaherty, K,; Carter, J,; Hochberg, E; Barnes, J.A,; Hamilton, A.M, et al. Zanubrutinib, obinutuzumab, and venetoclax with minimal residual disease-driven discontinuation in previously untreated patients with chronic lymphocytic leukaemia or small lymphocytic lymphoma: a multicentre, single-arm, phase 2 trial. Lancet Haematol. 2021, 8, e879-e890. 
60. Rossi, D,; De Almeida, J.M A new triplet for chronic lymphocytic leukaemia: zanubrutinib-venetoclax-obinutuzumab. Lancet Haematol. 2021, 8, e864-e865.

61. Chen, W.; Loury, D.J., Mody, T.D. Preparation of N-\{3-[2-(phenylamino)pyrimidin-4-ylamino]phenyl\} Amides as Inhibitors of Bruton's Tyrosine Kinase. WO 2013173518 A1. 2013 Nov 21.

62. Schafer, P.H,; Kivitz, A.J,; Ma, J,; Korish, S,; Sutherland, D,; Li, L,; Azaryan, A,; Kosek, J,; Adams, M; Capone, L,; et. al. Spebrutinib (CC-292) Affects Markers of B Cell Activation, Chemotaxis, and Osteoclasts in Patients with Rheumatoid Arthritis: Results from a Mechanistic Study. Rheumatol Ther. 2020, 7, 101-119.

63. Evans, E.K,; Tester, R,; Aslanian, S, Karp, R; Sheets, M, Labenski, M.T, et al. Inhibition of Btk with CC-292provides early pharmacodynamic assessment ofactivity in mice and humans. J. Pharmacoll. Exp. Ther. 2013, 346, 219-228.

64. Brown, J.R,; Harb, W.A,; Hill, B.T,; Gabrilove, J,; Sharman, J.P,; Schreeder, M.T,; Barr, P.M,; Foran, J.M,; Miller, T.P,; Burger, J.A,; et al. Phase I study of single-agent CC-292, a highly selective Bruton's tyrosine kinase inhibitor, in relapsed/refractory chronic lymphocytic leukemia. Haematologica 2016, 101, e295-298.

65. Caldwell, R.D,; Qiu, H,; Askew, B.C,; et al. Discovery of evobrutinib: an oral, potent, and highly selective, covalent Bruton's tyrosine kinase (BTK) inhibitor for the treatment of immunological diseases. J. Med. Chem. 2019, 62, 7643-7655.

66. Montalban, X.; Arnold, D. L.; Weber, M. S.; Staikov, I.; Piasecka-Stryczynska, K.; Willmer, J.; Martin, E. C.; Dangond, F.; Syed, S.; Wolinsky, J. on behalf of the Evobrutinib Phase 2 StudyGroup. Placebo-controlled trial of an oral BTK inhibitor in multiplesclerosis. N. Engl. J. Med. 2019, 380, 2406-2417.

67. Becker, A,; Martin, E.C,; Mitchell, D.Y,; et al. Safety, tolerability, pharmacokinetics, target occupancy, and concentration-QT analysis of the novel BTK inhibitor evobrutinib in healthy volunteers. Clin. Transl. Sci. 2020, 13, 325-336.

68. Montalban, X,; Arnold, D.L,; Weber, M.S,; et al. Placebo-controlled trial of an oral BTK inhibitor in multiple sclerosis. N. Engl. J. Med. 2019, 380, 2406-2417.

69. Walter, H.S.; Rule, S.A.; Dyer, M.J.; Karlin, L.; Jones, C.; Cazin, C.; Quittet, P.; Shah, N.; Hutchinson, C.V.; Honda, H.; et al. A phase 1 clinical trial of the selective BTK inhibitor ONO/GS-4059 in relapsed and refractory mature B-cell malignancies. Blood. 2016, 127, 411-419.

70. Yanxia Liu, Qingmin Yao, and Feng Zhang. Diagnosis, prognosis and treatment of primary central nervous system lymphoma in the elderly population (Review) Int. J. Oncol. 2021, 58, 371-387.

71. Walter HS, Jayne S, Rule SA, Cartron G, Morschhauser F, Macip S, Karlin L, Jones C, Herbaux C, Quittet P, et al. Long-term follow-up of patients with CLL treated with the selective Bruton's tyrosine kinase inhibitor ONO/GS-4059. Blood. 2017,129, 2808-2810.

72. Goess. C., Harris, C.M.; Murdock, S.; McCarthy „, R.W.; Sampson, E.; Twomey, R.; Mathieu, S.; Mario, R.; Perham, M.; Goedken ,E.R.; et al. ABBV-105, A selective and irreversible inhibitor of Bruton's tyrosine kinase, Is efficacious in multiple preclinical models of inflammation. Mod. Rheumatol. 2019, 29, 510-522.

73. Cai, X.; Qian, C.; He, Q.; Huang, Y.; Ma, Z.; Qin, S.; Ye, C.; Zhong, X. Preparation of dihydroimidazopyridine derivatives for treatment of Bruton's tyrosine kinase related diseases. CN 105753863 A. 2016 Jul 13

74. Reich, D.S,; Arnold, D.L,; Vermersch, P,; Bar-Or, A,; Fox, R.J,; Matta, A,; Turner, T,; Wallström, E,; Zhang, X, Mareš, $M$; ; et al. Tolebrutinib Phase $2 b$ Study Group. Safety and efficacy of tolebrutinib, an oral brain-penetrant BTK inhibitor, in relapsing multiple sclerosis: a phase $2 b$, randomised, double-blind, placebo-controlled trial. Lancet Neurol. 2021, 20, 729-738.

75. Tambaro, F.P,; De Novellis, D,; Wierda, W.G. The Role of BTK Inhibition in the Treatment of Chronic Lymphocytic Leukemia: A Clinical View. J. Exp. Pharmacol. 2021, 13, :923-935.

76. Lewis KL, Cheah CY.J. Non-Covalent BTK Inhibitors-The New BTKids on the Block for B-Cell Malignancies. Pers Med. 2021,11,764.

77. Michot, J.M, Ribrag, V. Pirtobrutinib shows evidence to inaugurate a third generation of BTK inhibitors. Lancet 2021, 397, 855-857.

78. Mato, A.R.; Shah, N.N.; Jurczak, W.; Cheah, C.Y.; Pagel, J.M.; Woyach, J.A.; Fakhri, B.; Eyre, T.A.; Lamanna, N.; Patel, M.R.; et al. Pirtobrutinib in relapsed or refractory B-cell malignancies (BRUIN): A phase 1/2 study. Lancet 2021, 397, 892-901.

79. Binnerts, M.E; Otipoby, K.L,; Hopkins, B.T. SNS-062 is a potent noncovalent BTK inhibitor with comparable activity against wide type BTK and BTK with an acquired resistance mutation [Abstract]. Mol .Cancer Ther. 2015, 14, C186.

80. Burger, J.A. Bruton tyrosine kinase inhibitors: present and future. Cancer J. 2019, 25, 386-393 
81. Byrd, J.C.; Smith, S.; Wagner-Johnston, N.; Sharman, J.; Chen, AI.; Advani, R.; Augustson, B.; Marlton, P.; Commerford, R.S.; Okrah, K.; et al. First-in-human phase 1 study of the BTK inhibitor GDC-0853 in relapsed or refractory B-cell NHL and CLL. Oncotarget. 2018, 9, 13023-35.

82. Reiff, S.D.; Muhowski, E.M.; Guinn, D.; Lehman, A.; Fabian, C.A.; Cheney, C.; Mantel, R.; Smith, L; Johnson, A.J; Young, W.B.; et al. Noncovalent inhibition of C481S Bruton tyrosine kinase by GDC-0853: a new treatment strategy for ibrutinib-resistant CLL. Blood. 2018, 132, 1039-1049.

83. Cohen, S,; Tuckwell, K,; Katsumoto, T.R,; Zhao, R,; Galanter. J,; Lee, C,; Rae, J,; Toth, B, Ramamoorthi, N,; et al. Fenebrutinib versus placebo or adalimumab in rheumatoid arthritis: a randomized, double-blind, phase II trial (ANDES Study). Arthritis Rheumatol. 2020, 72, 1435-1446.

84. Byrd, J.C.; Smith, S.; Wagner-Johnston, N.; Sharman, J.; Chen, AI.; Advani, R.; et al. First-in-human phase 1 study of the BTK inhibitor GDC-0853 in relapsed or refractory B-cell NHL and CLL. Oncotarget. 2018; 9, 13023-13035.

85. Langrish, L.L.; Bradshaw, J,M,; Michelle R. Francesco, M.R.; Owens, T.D,: Xing, Y.; Shu J.; LaStant, J.; Bisconte, A.; Outerbridge, C.; et al. preclinical efficacy and anti-inflammatory mechanisms of action of the bruton tyrosine kinase inhibitor rilzabrutinib for immune mediated visease. J. Immunol. 2021, 206, 1454-1468.

86. Murrell, D.F,; Patsatsi, A,; Stavropoulos; P,; Baum; S, Zeeli, T,; Kern, J.S,. Roussaki-Schulze, A.V,; Sinclair R, Bassukas, I.D.; Thomas, D,; et al. BELIEVE trial investigators. Proof of concept for the clinical effects of oral rilzabrutinib, the first Bruton tyrosine kinase inhibitor for pemphigus vulgaris: the phase II BELIEVE study. Br. J. Dermatol. 2021, 185, 745-755.

87. Reiff, S.D.; Mantel, R.; Smith, L.L.; Greene, J.T.; Muhowski, E.M.; Fabian, C.A.; Goettl. V.M.; Tran, M.; Harrington, B.K.; Rogers, K.A.; et al. The BTK inhibitor ARQ 531 targets ibrutinib-resistant CLL and Richter transformation. Cancer Discov. 2018, 8, 1300-1315

88. Reiff, S.D, Mantel R, Smith LL, et al. The BTK inhibitor ARQ 531 targets ibrutinib-resistant CLL and Richter transformation. Cancer Discov. 2018;8:1300-1315 .

89. Quinquenel, A,; Fornecker, L.M,; Letestu, R,; Ysebaert, L,; Fleury, C,; Lazarian, G,; Dilhuydy, M.S,; Nollet, D,; Guieze, R,; Feugier, P,; Roos-Weil, Det,; al Prevalence of BTK and PLCG2 mutations in a real-life CLL cohort still on ibrutinib after 3 years: a FILO group study. Blood 2019, 134, 641-644.

90. Bond, D.A,; Woyach, J.A. Targeting BTK in CLL: beyond Ibrutinib. Curr. Hematol. Malign. Rep. 2019 14, 197- 205;

91. Woyach, J.A, Furman, R.R,; Liu, T.M,; Ozer, H.G,; Zapatka, M, Ruppert, A.S, Xue L, Li DH, Steggerda SM, Versele et al. Resistance mechanisms for the Bruton's tyrosine kinase inhibitor ibrutinib. N. Engl. J. Med. 2014, 370, 2286-2294.

92. Woyach, J.A,; Ruppert, A.S,; Guinn, D,; Lehman. A,; Blachly, J.S., Lozanski, A,; Heerema, N.A,; Zhao, W,; Coleman, J,; Jones, D,; et al. BTK C481S-mediated resistance to ibrutinib in chronic lymphocytic leukemia. J. Clin. Oncol. 2017, 35, 1437-1443.

93. Woyach, J,; Huang, Y,; Rogers, K,; Bhat, S.A,; Grever, M.R,; Lozanski A, et al. Resistance to acalabrutinib in CLL is mediated Primarily by BTK Mutations [Abstract]. Blood 2019, 134(Suppl 1), 10.

94. Ran, F,; Liu, Y, Wang, C,; Xu Z, Zhang, Y,; Liu, Y,; Zhao, G,; Ling, Y. Review of the development of BTK inhibitors in overcoming the clinical limitations of ibrutinib. Eur. J. Med. Chem. 2021, 22, 114009.

95. George, B,; Chowdhury, S,M,; Hart, A,; Sircar, A,; Singh, S.K,; Nath, U.K.; Mamgain, M,; Singhal, N.K;, Sehgal, L,; Jain, N. Ibrutinib Resistance Mechanisms and Treatment Strategies for B-Cell lymphomas. Cancers (Basel). 2020, $12,1328$.

96. Wang, H,; Zhang, $\mathrm{W}$,; Yang, J,; Zhou, $\mathrm{K}$. The resistance mechanisms and treatment strategies of BTK inhibitors in B-cell lymphoma. Hematol, Oncol. 2021, 39, 605-615.

97. Bond, D.A.; Woyach, J.A. Targeting BTK in CLL: Beyond Ibrutinib. Curr Hematol Malig Rep. $2019,14,197-205$.

98. Jones, J.A; Mato, A;R;, Wierda, W.G,; Davids, M.S,; Choi, M; Cheson, B.D;, Furman, R.R,; Lamanna, N;, Barr, P.M,; Zhou, L,; Chyla, B; et al. Venetoclax for chronic lymphocytic leukaemia progressing after ibrutinib: an interim analysis of a multicentre, open-label, phase 2 trial. Lancet Oncol. 2018, 19, 65-75.

99. Skånland, S.S,; Mato, A.R. Overcoming resistance to targeted therapies in chronic lymphocytic leukemia. Blood Adv. 2021, 5, 334-343.

100. Robinson, H.R,; Qi, J; Cook, E.M,; Nichols, C,; Dadashian, E.L,; Underbayev, C,; Herman. SEM,; Saba, N.S,; Keyvanfar, K; Sun, C, et al. A CD19/CD3 bispecific antibody for effective immunotherapy of chronic lymphocytic leukemia in the ibrutinib era. Blood 2018, 132, 521-532.

101. Turtle, C.J,; Hay, K.A; Hanafi, L.A,; Li, D,; Cherian, S,; Chen, X,; Wood, B,; Lozanski, A,; Byrd, J.C.; Heimfeld, S,; et al. durable molecular remissions in chronic lymphocytic leukemia treated with CD19-specific chimeric antigen receptor-modified T Cells after failure of ibrutinib. J. Clin. Oncol. 2017, 35, 3010-3020. 
102. Siddiqi, T; Soumerai, J.D,; Dorritie, K,A,; Kathleen, A.; Dorritie, MD,; Deborah, M.; Stephens, P.A,; Riedell, J.E.; Arnason, J.E,; Kipps, T.J.: et al. Rapid undetectable MRD (uMRD) responses in patients with relapsed/refractory $(\mathrm{R} / \mathrm{R})$ chronic lymphocytic leukemia/small lymphocytic lymphoma (CLL/SLL) treated with lisocabtagene maraleucel (liso-cel), a CD19-directed CAR T cell product: updated results from Transcend CLL 004, a phase 1/2 study including patients with high-risk disease previously treated with ibrutinib. Blood 2019; 134 ( suppl 1): 503.

103. Sun, Y, ;Zhao, $\mathrm{X}$; Ding, N,; Gao, H,; Wu, Y,; Yang, Y, Z Zhao, M, Hwang, J,; Song, Y, Liu W, et al. PROTAC-induced BTK degradation as a novel therapy for mutated BTK C481S induced ibrutinib-resistant B-cell malignancies. Cell Res. 2018, 28, 779-781.

104. Hallek, M,; Al-Sawaf, O. Chronic lymphocytic leukemia: 2022 update on diagnostic and therapeutic procedures. Am. J. Hematol. 2021, 96, 1679-1705.

105. Smolewski, $\mathrm{P}, ;$ Robak, T. Current treatment of refractory/relapsed chronic lymphocytic leukemia: a focus on novel drugs. Acta Haematol. 2021, 144, 365-379.

106. O'Brien SM, Brown JR, Byrd JC, Furman RR, Ghia P, Sharman JP, Wierda WG. Monitoring and managing BTK inhibitor treatment-related adverse events in clinical practice. Front. Oncol. 2021, 11, 720704.

107. von Hundelshausen. P,; Siess, W. Bleeding by bruton tyrosine kinase-inhibitors: dependency on drug type and disease. Cancers (Basel) 2021, 13, 1103.

108. Shatzel, J.J,; Olson, S.R,; Tao, D.L,; McCarty, O.J.T,; Danilov, A.V,; DeLoughery, T.G. Ibrutinib-associated bleeding: pathogenesis, management and risk reduction strategies. J. Thromb. Haemost. 2017, 15, 835-847.

109. Caron, F,; Leong, D.P,; Hillis, C,; Fraser, G,; Siegal, D. current understanding of bleeding with ibrutinib use: a systematic review and meta-analysis. Blood Adv. 2017, 1, 772-778.

110. Bye, A.P,; Unsworth, A.J,; Desborough, M.J., Hildyard, C.A.T,; Appleby,; N, Bruce, D,; Kriek, N,; Nock, S.H,; Sage, T, Hughes, C.E; ; Gibbins, J.M. et al. Severe platelet dysfunction in NHL patients receiving ibrutinib is absent in patients receiving acalabrutinib. Blood Adv. 2017, 1, 2610-2623.

111. Tam, C.S,; Dimopoulos, M.A,; Garcia-Sanz R,; Trotman, J,; Opat, S,; Roberts, A.W,; Owen, R.G,; Song, Y,; Xu, W,; $\mathrm{Zhu}, \mathrm{J}$,; et al. Pooled safety analysis of zanubrutinib monotherapy in patients with B-cell malignancies. Blood Adv. 2021 Nov 1:bloodadvances.2021005621.

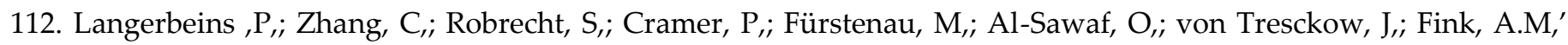
Kreuzer, K.A,; Vehling-Kaiser U, et al. The CLL12 trial: Ibrutinib versus placebo in treatment-naïve, early stage chronic lymphocytic leukemia. Blood 2021, 10:blood.2021010845.

113. Yun, S,; Vincelette, N.D,; Acharya, U,; Abraham I. Risk of atrial fibrillation and bleeding diathesis associated with ibrutinib treatment: a systematic review and pooled analysis of four randomized controlled trials. Clin. Lymphoma Myeloma Leuk. 2017, 17, 31-37.

114. Mato, A,R,; Nabhan, C,; Barr, P.M., Ujjani, C.S., Hill, B.T,; Lamanna, N,; Skarbnik, A.P,; Howlett C, Pu JJ, Sehgal $A R$, at al. Outcomes of CLL patients treated with sequential kinase inhibitor therapy: a real world experience. Blood 2016, 128, 199-2205.

115. Leong, D.P,; Caron, F,; Hillis, C,; Duan. A,; Healey, J.S,; Fraser, G,; Siegal, D. The risk of atrialfibrillation with ibrutinib use: a systematic review and meta-analysis. Blood, 2016, 128, 138-140.

116. Guha, A,; Derbala, M.H,; Zhao, Q, Wiczer, T.E,; Woyach, J.A,; Byrd, J.C,; Awan, F.T,; Addison D. Ventricular arrhythmias following ibrutinib initiation for lymphoid malignancies. J. Am. Coll. Cardiol. 2018, 72, 697-698.

117. Grewal, U.S,; Thotamgari, S.R,; Sheth, A.R,; Gaddam, S.J,; Ahmad. J,; Beedupalli, K,; Dominic P. Cardiovascular complications associated with novel agents in the chronic lymphocytic leukemia armamentarium: A pharmacovigilance analysis. Int. J. Cardiol. 2021, 344, 186-189.

118. Caldeira, D,; Alves, D,; Costa, J,; Ferreira J.J,; Pinto, F.J. Ibrutinib increases the risk of hypertension and atrial fibrillation: Systematic review and meta-analysis. PLoS One. 2019, 14, e0211228.

119. Binsah, G,; Philip, T.A,; Ferrajoli, A, et al. Anobservational study of the occurrence of atrial fibrillation and hypertension in patientstreated with ibrutinib [abstract]. Blood, 2014, 124. Abstract 565716.

120. O’Brien, S, ;Hillmen, P,; Coutre, S,; Barr, P.M,; Fraser, G,; Tedeschi, A,; Burger, J,A,; Dilhuydy, M.S,; Hess, G,; Moreno, $C_{i}$; et al. Safety analysis of four randomized controlled studies of ibrutinib in patients with chronic lymphocytic leukemia/small lymphocytic lymphoma or mantle cell lymphoma. Clin. Lymphoma Myeloma Leuk. 2018, 18, 648-657.

121. Dickerson, T,; Wiczer, T,; Waller, A,; Philippon, J,; Porter, K,; Haddad, D,; Guha, A,; Rogers K.A,; Bhat, S,; Byrd, J.C, et al. Hypertension and incident cardiovascular events following ibrutinib initiation. Blood 2019, 134, 1919-1928. 
122. Vitale, C,; Salvetti, C,; Griggio, V,; Porrazzo, M,; Schiattone, L,; Zamprogna, G,; Visentin, A,; Vassallo, F,; Cassin, R,; Rigolin, G.M,; et al. Preexisting and treatment-emergent autoimmune cytopenias in patients with CLL treated with targeted drugs. Blood 2021, 137, 3507-3517.

123. Noto, A,; Cassin, R,; Mattiello, V,; Reda, G. The Role of novel agents in treating CLL-associated autoimmune hemolytic anemia. J. Clin. Med. 2021, 10, 2064.

124. Ye, B,; Zhou, C,; Guo, H,; Zheng, M. Effects of BTK signalling in pathogenic microorganism infections. J Cell Mol Med. 2019, 23, 6522- 6529. McDonald C, Xanthopoulos C, Kostareli E. The role of Bruton's tyrosine kinase in the immune system and disease. Immunology 2021, 164, 722-736.

125. Pleyer, C,; Sun, C,; Desai, S; Ahn, I,E; Tian, X,; Nierman, P,; Soto, S,; Superata, J,; Valdez, J,; Lotter, J; Wiestner, A. Reconstitution of humoral immunity and decreased risk of infections in patients with chronic lymphocytic leukemia treated with Bruton tyrosine kinase inhibitors. Leuk Lymphoma 2020, 61, 2375-2382.

126. de Porto, .AP,; Liu, Z,; de Beer, R,; Florquin, S; de Boer, O.J,; Hendriks, R.W,; van der Poll, T,; de Vo,s AF. Btk inhibitor ibrutinib reduces inflammatory myeloid cell responses in the lung during murine pneumococcal pneumonia. Mol. Med. 2019 , 25, 3.

127. Florence, J.M,; Krupa, A,; Booshehri, L.M,; Davis, S.A,; Matthay, M.A,; Kurdowska, A.K. Inhibiting bruton's tyrosine kinase rescues mice from lethal influenza-induced acute lung injury. Am. J. Physiol. Lung Cell Mol.Physiol. 2018, 315, L52- 8.

128. Varughese, T,; Taur, $\mathrm{Y}, ;$ Cohen, $\mathrm{N}_{\text {; }}$ Palomba, M.L,; Seo, S.K,; Hohl, T.M,; Redelman-Sidi, G. Serious infections in patients receiving ibrutinib for treatment of lymphoid cancer. Clin. Infect. Dis. 2018, 67, 687-692.

129. Holowka, T,; Cheung, H; Malinis, M,; Gan, G,; Deng, Y,; Perreault. S,; Isufi, I,; Azar, M.M. Incidence and associated risk factors for invasive fungal infections and other serious infections in patients on ibrutinib. J. Infect. Chemother. 2021, 27, 1700-1705.

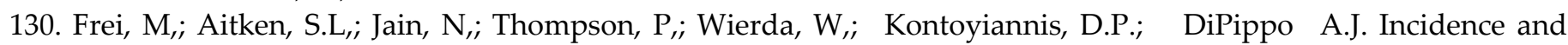
characterization of fungal infections in chronic lymphocytic leukemia patients receiving ibrutinib. Leuk. Lymphoma 2020, 6, 2488-2491.

131. Lipsky, A,; Lamanna, N. Managing toxicities of Bruton tyrosine kinase inhibitors. Hematology Am Soc Hematol Educ Program. 2020, 2020, 336-345;

132. Pleye, C,; Cohen, J,; Soto,S,; et al. Response to the Shingrix varicella zoster virus (VZV) vaccine in patients with chronic lymphocytic leukemia (CLL) that are treatment naive or treated with a Bruton's tyrosine kinase inhibitor (BTK-I). Blood 2019, 134, 3053.

133. Rhodes, J.M,; LoRe, V.A. 3rd,; Mato, A.R;, Chong E.A,; Barrientos, J.C,; Gerson, J.N,; Barta, S.K,; Landsburg. D.J,; Nasta, S.D,; Svoboda, J,; Loren, A.W,; Schuster, S.J. Ibrutinib-associated arthralgias/myalgias in patients with chronic lymphocytic leukemia: incidence and impact on clinical outcomes. Clin. Lymphoma Myeloma Leuk. 2020, 20, 438-444.

134. Roeker, L.E;, Eyre, T.A,; Thompson, M.C; Lamanna, N,; Coltoff, A.R,; Davids, M.S; Baker, P.O;, Leslie, L', Rogers, K.A,; Allan, J.N,; et al. Outcomes of front-line ibrutinib treated CLL patients excluded from landmark clinical trial. Am. J. Hematol. Blood 2021, 138, 1768-1773.

135. Mato, A, Jahnke, J, Li P,; Mehra, M,; Ladage, V.P.; Mahler, M.; Huntington,S.; Doshi, J.A.; et al. Real-world treatment and outcomes among older adults with chronic lymphocytic leukemia before the novel agents era. Haematologica 2018, 103, e462-e465.

136. Forum, U.C. Ibrutinib for relapsed/refractory chronic lymphocytic leukemia: a UK and Ireland analysis of outcomes in 315 patients. Haematologica 2016, 101, 1563-1572.

137. Stephens, D.M,; Byrd, J.C. How I manage ibrutinib intolerance and complications in patients with chronic lymphocytic leukemia. Blood 2019, 133, 1298-1307.

138. Awan, F.T., Schuh, A., Brown, J.R., Furman, R.R,; Pagel, J.M,; Hillmen, P,; Stephens DM, Woyach, J,; Bibikova, E; Charuworn, $\mathrm{P}$; i et al. Acalabrutinib monotherapy in patients with chronic lymphocytic leukemia who are intolerant to ibrutinib. Blood Advances. 2019, 3, 1553-1562.

139. Iberri, D.J,; Kwong, B.Y,; Stevens, L.A,; Coutre, S.E,; Kim, J,; Sabile, J.M,; Advani, R,H. Ibrutinib-associated rash: a single-centre experience of clinicopathological features and management. Br. J. Haematol. 2018, 180, 164-166.

140. Sibaud, V,; Beylot-Barry, M,; Protin, C,; Vigarios, E,; Recher, C,; Ysebaert, L. Dermatological Toxicities of Bruton's Tyrosine Kinase Inhibitors. Am. J. Clin. Dermatol. 2020, 21, 799-812.

141. Bitar, C,; Farooqui, M.Z.H,; Valdez, J,; Saba, N,S,; Soto, S,; Bray, A,; Marti, G,; Wiestner, A,; Cowen, E.W. Hair and nail changes during long-term therapy with ibrutinib for chronic lymphocytic leukemia. JAMA Dermatol. 2016, $152,698-701$. 
142. Abbas, H.A, Wierda, W.G. Acalabrutinib: A selective Bruton tyrosine kinase inhibitor for the treatment of B-Cell malignancies. Front. Oncol. 2021, 11, 668162.

143. Sun, $C_{r}$; Nierman, $\mathrm{P}_{r} ;$ Kendall, E.K, i et al. Clinical and biological implications of target occupancy in CLL treated with the BTK inhibitor acalabrutinib. Blood 2020, 13, 93-105.

144. Treon, SP, Castillo JJ, Skarbnik AP, Soumerai JD, Ghobrial IM, Guerrera ML, Meid, K,; Yang, G. The BTK inhibitor ibrutinib may protect against pulmonary injury in COVID-19 infected patients. Blood. 2020, 135, $1912-1915$.

145. Roschewski, M,; Lionakis, M.S,; Sharman, J.P,; Roswarski, J,; Goy, A,; Monticelli, M.A,; Roshon, M,; Wrzesinski, S.H,; Desai, J.V;, Zarakas, M.A,; et al. Inhibition of Bruton tyrosine kinase in patients with severe COVID-19. Sci. Immunol. 2020, 5, eabd0110.

146. Chong,; E.A,; Roeker, L.E,; Shadman, M,; Davids, M.S;, Schuster, S.J; , Mato, A.R. BTK inhibitors in cancer patients with COVID-19: "The winner will be the one who controls that chaos" (Napoleon Bonaparte). Clin Cancer Res. $2020 ; 26,3514-3516$.

147. Thibaud, S,; Tremblay, D,; Bhalla S,; Zimmerman, B,; Sigel, K,; Gabrilove, J. Protective role of Bruton tyrosine kinase inhibitors in patients with chronic lymphocytic leukaemia and COVID-19. Br. J. Haematol. 2020, 190, e73- 76. 